\title{
Anatomic and Molecular Imaging in Prostate Cancer
}

\author{
Eric T. Miller, ${ }^{1}$ Amirali Salmasi, ${ }^{1}$ and Robert E. Reiter ${ }^{1,2}$ \\ ${ }^{1}$ Department of Urology, David Geffen School of Medicine at UCLA, Los Angeles, California 90095 \\ ${ }^{2}$ Jonsson Comprehensive Cancer Center, David Geffen School of Medicine at UCLA, Los Angeles, \\ California 90095 \\ Correspondence: ericmiller@mednet.ucla.edu; rreiter@mednet.ucla.edu
}

\begin{abstract}
Prostate cancer is characterized by a complex set of heterogeneous disease states. This review aims to describe how imaging has been studied within each specific state. As physicians transition into an era of precision medicine, multiparametric magnetic resonance imaging $(\mathrm{mpMRI})$ is proving to be a powerful tool leading the way for a paradigm shift in the diagnosis and management of localized prostate cancer. With further research and development, molecular imaging modalities will likely change the way we approach recurrent and metastatic disease. Given the range of possible oncological progression patterns, a thorough understanding of the underlying carcinogenesis, as it relates to imaging, is a requisite if we are to appropriately manage prostate cancer in future decades.
\end{abstract}

$T_{\text {are }}^{\text {he }}$ he vast majority of prostate cancer diagnoses are linked to excellent survival outcomes. However, in men who have undergone definitive therapy, the risk of biochemical recurrence approaches 33\%-35\% within 10 years (Roehl et al. 2004; Bolton et al. 2014). By some estimates, recurrence following definitive therapy is associated with an $8 \%$ rate of progression to metastases and a $4 \%$ rate of prostate cancer-specific mortality within 8 years (Zelefsky et al. 2010). Approximately $4 \%$ of patients will present with metastatic disease at time of prostate cancer diagnosis and, when combined with men who progress from localized to metastatic castrationresistant disease, metastatic prostate cancer accounts for an estimated 26,000 to 30,000 deaths annually (SEER data at seer.cancer.gov/archive/ csr/1975_2013). The general disease states of prostate cancer can be modeled to include local- ized (T1-2, N0, M0), locally advanced (T3), or metastatic $(\mathrm{N} 1 / \mathrm{M} 1)$ prostate cancer (Scher and Heller 2000). This particular model of disease progression serves as a useful way to understand the role of imaging amid the complex and heterogeneous scope of prostate cancer management. For example, when a diagnosis of prostate cancer is suspected, an initial evaluation would be optimized with an imaging modality that correctly visualizes, localizes, and characterizes the primary tumor as indolent or lethal. Following confirmed diagnosis, imaging would ideally prognosticate and identify the extent of disease progression (localized vs. locally advanced), which would guide therapeutic options that are patient-specific and risk-adjusted. Highly accurate imaging modalities that correctly stage and then restage patients following therapy would minimize use of empiric and/or nondirected

Editors: Michael M. Shen and Mark A. Rubin

Additional Perspectives on Prostate Cancer available at www.perspectivesinmedicine.org

Copyright (C) 2018 Cold Spring Harbor Laboratory Press; all rights reserved; doi: 10.1101/cshperspect.a030619

Cite this article as Cold Spring Harb Perspect Med 2018;8:a030619 
E.T. Miller et al.

therapies that expose patients to unnecessary risk with little benefit. Finally, given that metastatic disease accounts for all disease-specific mortality, novel imaging modalities would maximize our understanding of tumor biology in the metastatic state, identify treatment options that extend beyond palliative benefits, and help prognosticate time to castrate resistance and/or survival (see Fig. 1).

This review outlines how prostate cancer imaging has already started to fill the very important roles within each disease state. Furthermore, it illustrates the pitfalls and limitations that still exist. Needless to say, the use of imaging within prostate cancer management is a rapidly growing field that will undoubtedly supplement and alter our current practice patterns on a global basis.

\section{ULTRASOUND IMAGING}

The standard of care for detection of primary prostate cancer has long been based on techniques that rely on grayscale transrectal ultrasound (TRUS) (Carter et al. 2013). Its use became common in the early 1990s as physicians transitioned from digitally guided biopsies to ultrasound (US)-guided techniques (Hodge et al. 1989). Although initial image-guided biopsies followed a standard sextant template, a 12-core approach was adopted when studies found a significant improvement in prostate cancer detection (Taira et al. 2010). For a short period, saturation biopsy techniques were thought to increase detection of significant prostate cancer (Stewart et al. 2001). With time, most physicians have abandoned the sat-

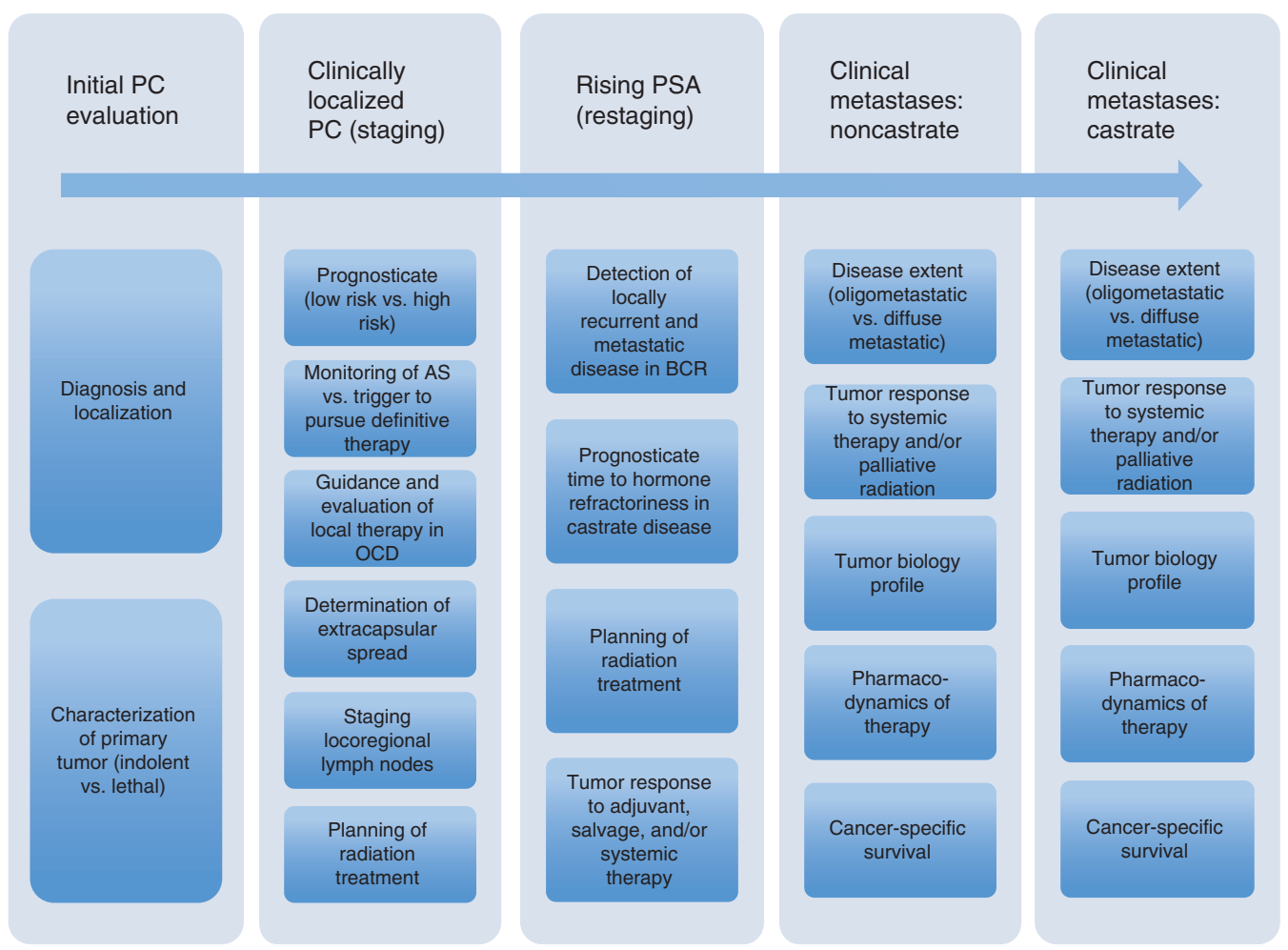

Figure 1. The current and potential roles of imaging in prostate cancer. Prostate cancer is a heterogeneous disease with multiple phases and states. As we enter into an era of precision medicine, prostate cancer imaging will be tailored to address the specific characteristics that define each disease state and, more importantly, each patient. Novel modalities in combination with those that are well founded will be applied along this continuum to achieve optimal accuracy. OCD, Organ-confined disease; PSA, prostate-specific antigen; AS, active surveillance; PC, prostate cancer; BCR, biochemical recurrence. 
uration technique in large part because of evidence showing that it introduces the unwarranted risk of urinary retention and hematuria requiring treatment (Eichler et al. 2006; Jones et al. 2006; Ashley et al. 2008).

Although early results were promising, the limitations of TRUS-guided biopsies were soon recognized. Using TRUS-guided biopsies alone, an estimated $21 \%-47 \%$ of tumors go unrecognized on initial biopsy (Singh et al. 2004; Taira et al. 2010). Men who continue to have an elevated risk of prostate cancer but have no detectable cancer on biopsy are often exposed to multiple repeat procedures (Welch et al. 2007). In parallel with this clinical dilemma, widespread adoption of the "systematic" 12 -core techniques led to a sharp increase in incidental detection of indolent tumors (Cooperberg et al. 2007). Some investigators argue that TRUS-guided biopsy is a blind approach that detects clinically insignificant tumors at a rate as high as $40 \%$ (Zaytoun et al. 2011; Marks et al. 2013). Multiple schemes have attempted to improve accuracy by sampling the lateral peripheral zone and anterior apex, but TRUS-guided prostate biopsies remain nonspecific to both the tumor and the patient (Eskew et al. 1997; Chon et al. 2002; Presti et al. 2003).

Supplementary US-based techniques and technologies have been developed and studied to augment TRUS-guided biopsies. A summary of US techniques is presented in Table 1. In general, US technologies are understudied and/or limited by poor reproducibility, variable tumordependent resolution, and poor whole-gland visualization (Grabski et al. 2011; Schiffmann et al. 2015). These drawbacks and challenges have paved the way for use of multiparametric magnetic resonance imaging (mpMRI) in the diagnosis and management of prostate cancer.

\section{MULTIPARAMETRIC MAGNETIC RESONANCE IMAGING}

When applied to imaging of the prostate gland, mpMRI combines functional, anatomical, and biological information to optimize differentiation of benign from malignant features. The foundation of mpMRI rests on morphological
T2-weighted imaging (T2WI), which is supplemented with functional imaging techniques known as diffusion weighted imaging (DWI) and dynamic contrast enhancement (DCE) (Felker et al. 2016). Magnetic resonance spectroscopy (MRSI) was introduced as an additional technique to detect prostate cancer and takes advantage of the relative concentrations of cellular metabolites (Seitz et al. 2009).

\section{T2-Weighted Imaging}

T2WI provides the highest resolution to evaluate key morphological changes that occur in prostate cancer. In a normal gland, the peripheral zone is composed of abundant ductal and acinar elements, which contain increased water content relative to other anatomical regions of the prostate. The peripheral zone, therefore, has high and homogenous signal intensity. By comparison, the transition zone bears fewer glandular components, less water content, and is therefore slightly darker with varying signal intensity (Bhavsar and Verma 2014). Prostate cancer within the peripheral zone develops as a lowsignal intensity focus distinct from surrounding high-intensity tissue. Prostatitis, atrophy, and/ or hemorrhage appear as similar low-signal intensity foci. Prostate cancer in the transition zone is more difficult to detect and presents as an ill-defined, homogeneous, moderately hypointense (i.e., darker) focus. Benign prostatic hyperplasia $(\mathrm{BPH})$ nodules are similar in appearance and an "erased charcoal" or "smudgy fingerprint" have been described to distinguish clinically significant cancer from benign tissue (Bhavsar and Verma 2014; Weinreb et al. 2016). Finally, T2WI is an important component of clinical staging as it illuminates the prostate capsule, neurovascular bundles, seminal vesicles, and anterior stromal components (Felker et al. 2016).

\section{Diffusion-Weighted Imaging}

DWI is a functional imaging technique that measures the random motion of water molecules within the intravascular, intracellular, and extracellular compartments. Differences in 
E.T. Miller et al.

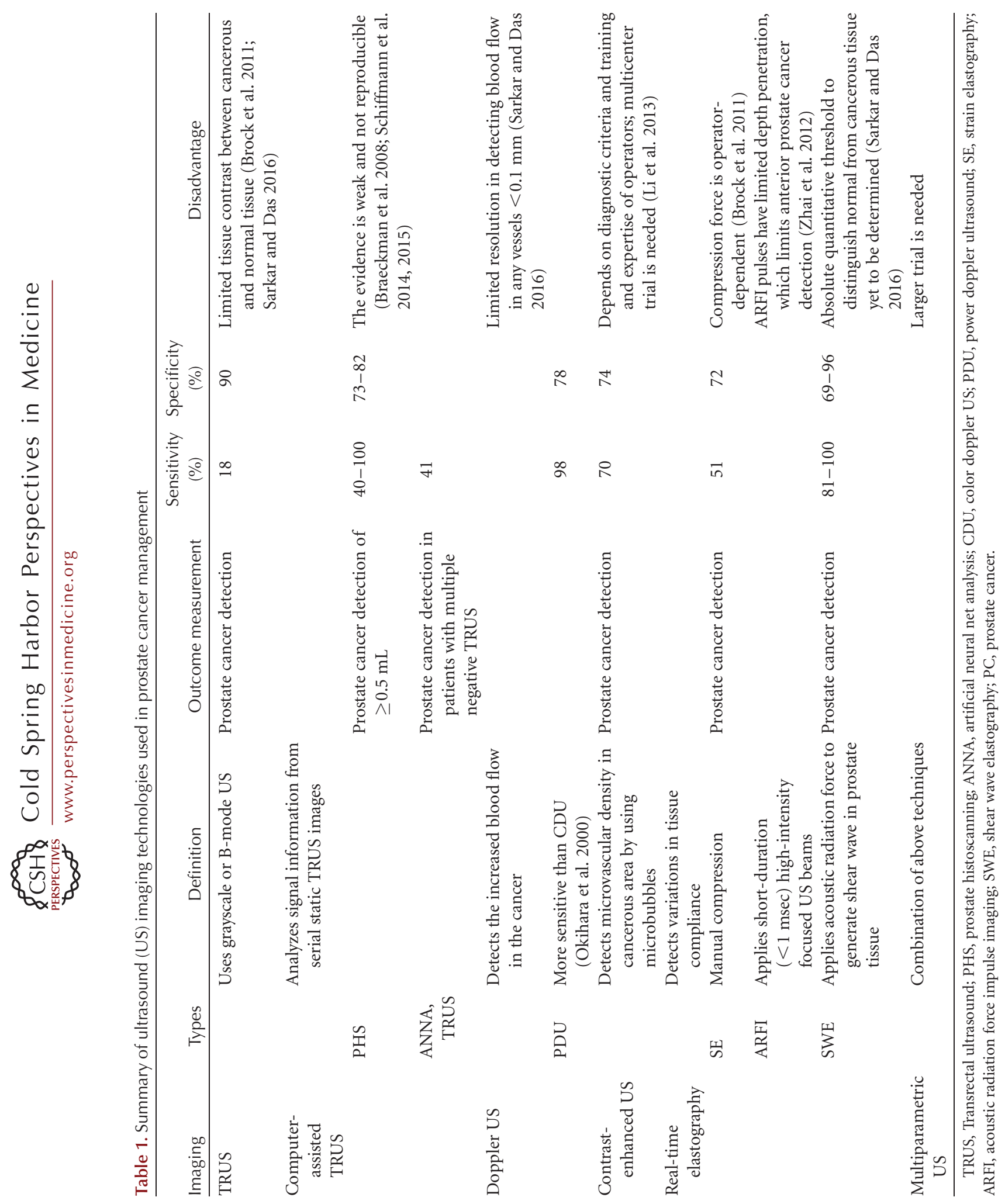


cellularity and cell membrane integrity impede free diffusion of water, which can be used to characterize biological tissues (Qayyum 2009). An apparent diffusion coefficient (ADC) map is constructed and measures the magnitude of diffusion. ADC is calculated by plotting the logarithm of relative signal intensity ( $y$-axis) against multiple $b$-values ( $x$-axis), in which $b$-value refers to the applied magnetic field duration and strength (i.e., diffusion-sensitizing gradient). Prostate cancer tissue is most often composed of highly dense tumor cells that restrict the random motion of water molecules in the extracellular space. With increased restriction of water diffusion in cancerous tissue there is less signal loss and malignant prostate tissue appears as a bright, hyperintense region on high $b$-value DWI. On ADC maps, prostate cancer appears as hypointense dark spots (Verma et al. 2011). As a clinical tool, ADC has been shown to correlate well with increased D'Amico and Gleason scores (i.e., measures of aggressiveness) when compared with pathology staging of patients who underwent radical prostatectomy (Hambrock et al. 2011; Turkbey et al. 2011).

\section{Dynamic Contrast-Enhanced Imaging}

DCE-MRI evaluates serial T1-weighted images collected before, during, and after injection of an intravenous contrast agent, such as low molecular weight gadolinium. This technique relies on increased neovascularity that arises during tumor growth and development. With increased tumor-driven angiogenesis, microvessels that develop within prostate cancer are weak, permeable, and disorganized, which leads to early enhancement and brisk wash-out (Verma et al. 2012). Studies have shown that DCE-MRI improves tumor detection when compared with T2WI alone (Tan et al. 2015).

\section{Magnetic Resonance Spectroscopic Imaging}

Healthy, well-organized prostate glands synthesize, store, and secrete citrate. By comparison, because of intrinsic cellular alterations, citrate production is dramatically reduced in prostate cancer. Choline plays an important role in me- tabolism of cellular membranes and choline concentration is markedly increased in densely packed highly cellular prostate cancer. Changes in choline-to-citrate ratio are well studied and MRSI has been used to improve detection, localization, volume estimation, and organ-confinement status at multiple stages of prostate cancer treatment and follow-up (Kurhanewicz and Vigneron 2008). Of note, the spectroscopic resonant peak of creatine and choline are similar; thus, the sum of these two metabolites are taken and used to calculate a ratio over citrate (Kurhanewicz et al. 2000). Analyzing MRSI readouts is a highly technical task with a high degree of inter-reader variability, thus its uses in common clinical applications are limited to trained experts (Felker et al. 2016; Sarkar and Das 2016).

\section{Endorectal Coil and 3.0T MRI}

Obtaining high-quality mpMRI images is of utmost importance when evaluating the role of MRI in staging and characterization of prostate cancer. The prostate's pelvic location and small size adds a high degree of noise during image acquisition. The use of an endorectal coil has been shown to improve the signal-to-noise ratio by almost 10-fold (Margolis 2014). In settings in which only $1.5 \mathrm{~T}$ MRI is available, use of an endorectal coil is currently recommended (Shah et al. 2015). However, the use of an endorectal coil with 3.0T MRI remains controversial, as the gradient performance of 3.0T MRI alone gains little benefit from use of a concurrent coil (Ghai and Haider 2015). In general, the main benefit of an endorectal coil is thought to be related to increased resolution of the prostate capsule as well as improved ability to obtain high-quality DWI and MRSI sequences (Beyersdorff et al. 2005). If further research supports the finding that use of an endorectal coil can significantly improve image resolution in the pelvis, then endorectal coils would effectively improve staging accuracy, which would have direct implications for surgical planning as well as radiation therapy guidance. At this point, current guidelines recommend use of 3.0T magnet MRI, which appears to be equivalent to use of a 
E.T. Miller et al.

1.5T MRI with an endorectal coil (Park et al. 2007; Mohler et al. 2016).

\section{THE USE OF MRI IN THE DIAGNOSIS OF PROSTATE CANCER}

Prostate cancer is a complex disease characterized by pathological features and clinical outcomes that bear a high degree of variability (Fischer et al. 2015; Gordetsky and Epstein 2016). Although current guidelines support management of low-risk prostate cancer with active surveillance (AS) protocols, many large studies have shown the importance of providing curative-intent treatment in men with intermediate and high-risk disease (Cooperberg et al. 2007; Wilt et al. 2012; Bill-Axelson et al. 2014; Mohler et al. 2014). Nearly every currently available prostate cancer risk nomogram relies on Gleason grade and/or tumor volume for appropriate risk stratification (D'Amico et al. 1998; Cooperberg et al. 2005; Mohler et al. 2014). Therefore, accurate, reliable, highly sensitive, and specific imaging techniques are necessary if we are to provide high-quality care to men with suspected and/or proven prostate cancer.

\section{STANDARDIZATION OF PROSTATE CANCER DETECTION BY MRI}

\section{Prostate Cancer Reporting Systems}

For mpMRI to gain wide acceptance in the diagnosis and detection of prostate cancer, standard scanning-acquisition protocols and reading techniques are vital. The first version of the Prostate Imaging and Reporting Data System (PI-RADS v1) was published by the European Society of Urogenital Radiology in 2012 (Barentsz et al. 2012). A second version of PIRADS (v2) was released in 2014 and emphasizes the use of certain sequences when assessing specific zones of the prostate (Weinreb et al. 2016). The level or grade of cancer suspicion was refined to a 5 -point scale stratified by three pulse sequences (T2WI, DWI, and DCE). Studies have shown good-to-moderate inter-reader agreement with the PI-RADS v2 system and concluded that it is appropriate for use as a stan- dardized scoring system in prostate cancer detection (Schimmoller et al. 2013).

A second validated prostate MRI scoring system designed for use by researchers at the University of California, Los Angeles (UCLA) uses a 5-point scoring system based on T2WI characteristics, quantitative $\mathrm{ADC}$, and $\mathrm{DCE}$ curve analysis (see Table 2). It is unique in that it designates the specific use of DWI and T2WI for assessment of the prostates peripheral and transitional zones, respectively. It is also distinct in that it uses "quantitative" measures of ADC and DCE sequences, whereas PI-RADS v2 uses only qualitative measures (Sonn et al. 2013; Le et al. 2014; Weinreb et al. 2016).

A third MRI-scoring system has been developed by the National Institutes of Health (NIH) and uses a 3-point scale (low, moderate, and high) to assign prostate cancer suspicion (RaisBahrami et al. 2013). Similar to PI-RADS v2, it involves qualitative assessment of DWI and DCE pulse sequences but does not assign a dominant sequence for evaluation of prostate zones (Turkbey et al. 2013).

The PI-RADS v2 system is widely accepted as the global standard for reporting mpMRI findings when imaging the prostate gland. Although the aforementioned guidelines have been proposed, they are often institution-specific and have been used to supplement ongoing research studies.

\section{MRI-GUIDED LOCALIZATION AND PROSTATE BIOPSY TECHNIQUES}

With refinements to the aforementioned standard reporting protocols and improved understanding of concordance between mpMRI and pathological outcomes, deployment of mpMRI in the identification and diagnosis of clinically significant malignancies is becoming integral to prostate cancer management. Multiparametric MRI-driven biopsy techniques, paired with high-quality standardized reporting platforms, have emerged as burgeoning approaches that improve safety, efficiency, and increased identification and detection of clinically significant tumors (Moore et al. 2013). More specifically, MRI-fusion techniques use the familiar B- 
Imaging in Prostate Cancer

Table 2. Summary of MRI classification system based on T2WI, quantitative ADC, and DCE sequences

\begin{tabular}{|c|c|c|c|}
\hline $\begin{array}{l}\text { Image } \\
\text { grade }\end{array}$ & T2-weighted imaging (T2WI) & $\begin{array}{l}\text { Apparent diffusion } \\
\text { coefficient (ADC) }\end{array}$ & Dynamic contrast enhancement (DCE) \\
\hline 1 & Normal & $>1.4 \times 10^{-3} \mathrm{~m}^{2} / \mathrm{sec}$ & Normal \\
\hline 2 & Faint decreased signal & $\begin{array}{l}1.2-1.4 \times \\
10^{-3} \mathrm{~m}^{2} / \mathrm{sec}\end{array}$ & $\begin{array}{l}\text { Intense or early enhancement (mild } \\
\text { abnormal) }\end{array}$ \\
\hline 3 & $\begin{array}{l}\text { Distinct low signal (moderate } \\
\text { dark nodule) }\end{array}$ & $\begin{array}{l}1.0-1.2 \times \\
10^{-3} \mathrm{~m}^{2} / \mathrm{sec}\end{array}$ & $\begin{array}{l}\text { Intense and early enhancement, or early } \\
\text { enhancement with washout (moderate } \\
\text { abnormal) }\end{array}$ \\
\hline 4 & $\begin{array}{l}\text { Markedly decreased signal } \\
\text { (intense dark nodule) }\end{array}$ & $\begin{array}{l}0.8-1.0 \times \\
10^{-3} \mathrm{~m}^{2} / \mathrm{sec}\end{array}$ & $\begin{array}{l}\text { Intense and early enhancement with } \\
\text { washout (high abnormal) }\end{array}$ \\
\hline 5 & $\begin{array}{l}\text { Focal low signal with mass } \\
\text { effect (dark nodule with } \\
\text { mass effect) }\end{array}$ & $<0.8 \times 10^{-3} \mathrm{~m}^{2} / \mathrm{sec}$ & $\begin{array}{l}\text { Early enhancement is intense with } \\
\text { immediate washout (profound } \\
\text { abnormal) }\end{array}$ \\
\hline
\end{tabular}

Data from Natarajan et al. (2011b) and Sonn et al. (2013).

mode, TRUS, to acquire live images of the prostate, which are then "fused" in real time with previously performed and reported pelvic mpMRI scans. Fusion techniques can range from expert cognitive fusion to commercially available software-based MRI-US fusion devices. By comparison, in-bore MRI-guided prostate biopsies are performed directly in the bore of an MRI scanner. The following sections describe these techniques and their applications in more detail.

\section{MRI-Cognitive Fusion Prostate Biopsy}

The first step when performing a cognitive fusion prostate biopsy involves a thorough review of a previously acquired pelvic mpMRI. If a suspicious prostate lesion is detected, then the MRI-derived prostate targets are "stored" in the cognitive domain of the performing physician. ATRUS probe is used to direct the biopsy needle toward the anatomic space occupied by the abnormal lesion. The technique is highly dependent on the skill and experience of the performing physician; therefore, it has been an area of intense research and review (Moore et al. 2013).

Investigators in France studied a large group of 555 men who underwent mpMRI before their first-ever prostate biopsy. All men underwent standard 10-12 TRUS-guided systematic biopsies, whereby $63 \%$ of men had suspicious lesions detected on mpMRI and had two additional cognitive-targeted biopsies aimed at all suspi- cious areas. The investigators conclude that the detection accuracy of significant prostate cancer with cognitively targeted biopsies was significantly better than extended systematic biopsies $(p<0.001)$. Targeted biopsies detected about 16\% more high-grade cases than extended biopsies. Importantly, the investigators estimated that $13 \%$ of patients with positive MRIs avoided the unnecessary diagnosis of nonsignificant prostate cancers (Haffner et al. 2011).

The role of cognitive fusion in men with prior negative biopsies has also been studied. Sciarra et al. found that the addition of mpMRI and cognitive fusion improved the cancer detection rate to $88 \%$ in men who had two prior negative systematic TRUS-guided biopsies (Sciarra et al. 2010). Labanaris et al. (2010) performed extended 18-core TRUS biopsies in men with a prior negative biopsy. Those with suspicious lesions on MRI had additional cognitive targeting, whereby the cancer detection rate was $56 \%$ and $18 \%$ for targeted and systematic cores, respectively. The presence of a suspicious MRI improved cancer detection to $74 \%$ versus $19 \%$ in those with no suspicious lesions on MRI. They concluded that the sensitivity of their technique approached 81\% (Labanaris et al. 2010).

Wysock et al. (2014) prospectively compared outcomes between visual targeting and MRI-US fusion-targeted biopsies in the same patient. In this study, 125 consecutive men underwent targeted biopsy of suspicious regions that were seen on mpMRI. A single operator 
E.T. Miller et al.

performed MRI-US fusion targeted biopsy at the mpMRI-designated regions of suspicion. A second blinded operator then performed a systematic biopsy in addition to visually targeted cognitive fusion biopsy in the same patient. In total, 172 targets were identified. When the two techniques were compared, there was no significant difference between detected cancers but there was improved detection of Gleason sum $\geq 7$ cancers in the MRI-US fusion targets. Not surprisingly, the benefits of MRI-US fusion biopsy were shown with better detection of smaller lesions. Furthermore, MRI-US fusion appeared to improve detection of nonmalignant lesions, which may be an indication that the identified region of suspicion was hit and was in fact a true negative. The main weakness of the study, however, was its small sample size. Larger studies asking similar questions are needed before either technique is proven optimal ( $\mathrm{Wy}-$ sock et al. 2014). In a similar study by Cool et al. (2014), which also compared MRI-US fusion to cognitive fusion biopsies, the investigators concluded that cognitive fusion was inferior to MRI-US fusion when applied to all operators at all levels of experience. In their study, the largest differences in cancer detection appeared to be related to targeting of tumors in the apex, mid-gland, and anterior regions, whereby $<50 \%$ of clinically significant cancers were detected with the cognitive fusion technique (Cool et al. 2014).

Most investigators have supported the notion that cognitive targeting is a promising approach with improved detection of clinically significant cancer and concurrent reduction in detection of insignificant ones (Comet-Batlle et al. 2003; Park et al. 2011). Unfortunately, the variability of data collection protocols, patient selection, systematic templates, MRI protocols, operator performance, and radiological experience makes comparison difficult. Further validation is needed before widespread application among community physicians.

\section{In-Bore MRI-Guided Prostate Biopsy}

Techniques have been established that allow for direct in-bore MRI-guided prostate biopsy. In- bore MRI biopsies are preceded by acquisition of a separate pelvic mpMRI, which attempts to identify suspicious lesions that will be directly targeted under rescanning at time of biopsy. In leading studies, cancer detection rates using inbore technology in patients with prior negative prostate biopsies were between $38 \%$ and 59\%. From similar studies, the percentage detection of clinically significant cancers ranged from $81 \%$ to $93 \%$ (Engelhard et al. 2006; Hambrock et al. 2010; Roethke et al. 2012).

One major difference with this technique is that patients undergoing in-bore MRI biopsies require sedation or general anesthesia. Furthermore, tissue procurement takes significantly longer than other MRI-US fusion methods, which limits the ability to collect additional systematic template biopsies (Engelhard et al. 2006; Hambrock et al. 2010; Roethke et al. 2012).

\section{Software-Based MRI-Fusion Biopsy Devices}

Numerous platforms currently exist within the realm of MRI-US fusion biopsy devices. These devices have been designed for use under local anesthesia in the outpatient setting. Commercially available devices store previously acquired MRI images and superimpose (coregister) realtime TRUS images, which enables the targeted biopsy of suspicious lesions. Each platform and software system differs by tracking mechanism (electromagnetic vs. electromechanical), US image acquisition (3D volumetric vs. 2D sweep), and biopsy route (transrectal vs. transperineal). A thorough description of the technology behind each platform has been reviewed (Natarajan et al. 2011a; Marks et al. 2013; Le et al. 2014; Sarkar and Das 2016). Marks et al. (2013) summarized the current MRI-US fusion devices approved by the U.S. Food and Drug Administration (FDA) in a recent review article.

\section{THE IMPACT OF MRI ON LOCALIZED PROSTATE CANCER MANAGEMENT}

\section{MRI-US Fusion Biopsy}

As described in the prior sections, prostate biopsies guided by MRI-US fusion techniques 
have been shown to improve detection of prostate cancer in both biopsy-naïve men and men with prior negative biopsies (Abd-Alazeez et al. 2014; Sonn et al. 2014). However, a precise understanding of all variables that effect and influence image-guided techniques are not yet established. Ongoing studies have continued to elucidate the factors that affect outcomes related to accuracy, predictive values, sensitivity, and specificity.

To directly assess predictors of prostate cancer detection by mpMRI, Le et al. (2015) performed a retrospective analysis of 122 consecutive men who underwent mpMRI before radical prostatectomy. After determining the concordance between radiological and whole-mount pathology, a multivariate logistic regression model predicting the odds of tumor detection found that index (dominant) tumor status, prostate weight, and size were significant predictors of detection. Overall sensitivity for tumor detection was increased for Gleason score $\geq 7(72 \%)$, larger $>1 \mathrm{~cm}(72 \%)$, and index tumors $(80 \%)$. The detection of nonindex lesions in multifocal prostate cancer was poor, which is an important finding in light of potential focal prostate cancer therapies (Le et al. 2015). This study was key to illustrating that prostate cancer detection is influenced by specific measureable variables. However, it also showed that $\sim 28 \%$ of prostate tumors with Gleason score $\geq 7$ go undetected, thus indicating that other variables or techniques still need further investigation.

Given that a certain percentage of tumors still go undetected on mpMRI, Filson et al. (2016) were interested in determining precise performance parameters that effect detection of clinically significant cancer when using MRI-US fusion biopsy. In a prospective study, a total of 1042 men underwent mpMRI and MRI-US fusion biopsy. Biopsies included both systematic and targeted biopsies. Their main findings were that if higher grades were assigned to the regions of interest that underwent targeted biopsy, there was increased risk of finding clinically significant tumors. In addition, a higher overall prostate-specific antigen (PSA) density appeared to predict the finding of significant tumors. With regard to the technique, they found that combining targeted and systematic biopsies resulted in an increased detection of significant cancer. Finally, $\sim 16 \%$ of men had clinically significant cancer with no suspicious finding on the mpMRI (Filson et al. 2016).

With increased use of MRI-US fusion biopsies in the detection of clinically significant prostate tumors, several factors still require investigation. Given that the technique is extremely user-dependent and requires great experience by radiologists and urologists, further validation of the MRI grading systems are needed. This step must happen in unison with increased access to imaging centers and reimbursement options for ideal imaging modalities. Establishing a standardized technique is still needed to allow for cost-favorable, widespread, and efficient adoption at other community and academic centers. Finally, a better understanding of other variables, such as those that lead to positive biopsies in the setting of a negative mpMRI, are needed to help make this a powerful and accurate clinical tool (Bockholt and Marks 2015).

\section{The Role of MRI in AS}

As studies continue to support the notion that MRI increases the detection of clinically significant tumors, mpMRI has been evaluated for its potential role in improving selection and monitoring of patients on AS. Multiple research groups have attempted to construct predictive tools that link mpMRI with final pathology findings.

Vargas et al. (2012) studied 388 consecutive men who were initially diagnosed with low-risk prostate cancer. These men underwent mpMRI before an institution-specific confirmatory biopsy. Three independent radiologists used a 5point scale to score the likelihood of a tumor presence based on mpMRI findings. A score of $\leq 2$ had high specificity and negative predictive value (NPV) for upgrading on confirmatory biopsy. A multivariate model showed that patients with a score of 5 were significantly more likely to have upgraded pathology on confirmatory biopsy (Vargas et al. 2012). In a similar study, Stamatakis et al. (2013) retrospectively 
E.T. Miller et al.

studied men who underwent MRI-US fusion prostate biopsy. In 85 men who met the criteria for AS, the initial mpMRI findings were assessed with regard to prostate volume, lesion density, lesion volume, lesion diameter, and total lesion number. Logistic analysis found significant association between AS reclassification and lesion density, highest MRI lesion suspicion, and number of lesions, whereby $29 \%$ of patient were reclassified as not meeting criteria for AS (Stamatakis et al. 2013). By comparison, some studies found that the simple existence of mpMRI visible cancer is significantly associated with unfavorable disease and even disease progression (Fradet et al. 2010; Park et al. 2014).

In a retrospective study of 115 men by Chamie et al. (2014), predictive values, sensitivity, and specificity of the Epstein criteria (PSA $\leq 10 \mathrm{ng} / \mathrm{mL}$, Gleason score $\leq 6,<3$ positive biopsy cores, whereby none have $>50 \%$ involvement by cancer) (Epstein et al. 1994) with or without mpMRI, were studied to predict men's suitability for AS based on postprostatectomy whole-mount pathology. Men included in the study underwent mpMRI and robotically assisted laparoscopic prostatectomy (RALP), whereby 11 men were excluded for poor quality mpMRI. Pathologic outcomes were determined for all men; 46 men were classified low-risk and 58 men were classified highrisk. In patients who were pathologically staged with Gleason 7 or pT3 prostate cancer, 12 patients with significant disease were incorrectly assigned to insignificant disease categories based on Epstein criteria alone (NPV of 68\% and sensitivity of 79\%). When DWI, through $\mathrm{ADC}<850 \mu \mathrm{m}^{2} / \mathrm{sec}$, was added to Epstein's criteria, the sensitivity and NPV improved to 93\% and 84\%, respectively. Thus, Epstein's criteria incorrectly assigned low-risk disease $\sim 32 \%$ of the time in comparison to a rate of $7 \%$ when $\mathrm{ADC}<850 \mu \mathrm{m}^{2} / \mathrm{sec}$ was added. An additional finding was that MRI improved detection rates of Gleason $\geq 7$ tumors of any size as well as large Gleason 6 tumors. The addition of MRI to known clinical staging criteria may more accurately identify significant cancer and thus may reduce failure rates on AS (Chamie et al. 2014).
The direct role of mpMRI in identifying potential AS candidates is not yet firmly established, but practice patterns are shifting. The most recent version of management guidelines developed by the National Comprehensive Cancer Network (NCCN) supports the use of mpMRI when anterior and/or aggressive prostate cancers are suspected in the setting of a rising PSA and negative systematic biopsies (Mohler et al. 2016). However, despite directed AS studies with reported NPVs of $>95 \%$, as well as a sensitivity and accuracy as high as 93\% and 92\%, respectively, further high-quality validation studies are needed before mpMRI can be confidently incorporated into AS protocols (Villers et al. 2006; Turkbey et al. 2013).

\section{Clinical Staging and Guidance for Definitive Treatment Management}

Nerve-sparing approaches help decrease the risk of incontinence and impotence following open and laparoscopic radical retropubic prostatectomies (Walsh et al. 1983; Box and Ahlering 2008). In relation, a positive surgical margin has significant prognostic significance when predicting the chance of biochemical recurrence. These facts weigh heavily on the mind of the surgeon when planning the extent of surgical resection. A more conservative resection increases the chance of a positive margin and future disease recurrence, whereas wider resection increases the risk of comorbid conditions. Given that assessment of clinical stage by digital rectal examination has high interobserver variability and poor accuracy, many groups have proposed the use of imaging to more accurately identify clinical stage and aid in preoperative planning.

Somford et al. (2013) evaluated 183 patients who underwent preoperative evaluation with mpMRI and endorectal coil before radical prostatectomy. Low, intermediate, and high-risk groups were established based on the D'Amico criteria (D'Amico et al. 1998). Using mpMRI, the overall staging accuracy was a $74 \%$. Most importantly however, the positive predictive value of mpMRI was $88.8 \%$ in the high-risk 
Imaging in Prostate Cancer

group, whereas it was a mere $33.3 \%$ in the lowrisk group. In contrast, the NPV was $87.7 \%$ in the low-risk cohort, whereas it was only $38.1 \%$ in the high-risk cohort. The investigators smartly concluded that use of mpMRI to assess the absence of extraprostatic extension is best reserved for patients with low-risk disease. Furthermore, they suggested that because high-risk patients bear a high positive predictive value for extraprostatic extension, this might aid in reducing the risk of positive surgical margins during non-nerve-sparing techniques (Somford et al. 2013).

In an attempt to provide information that would influence surgical margin status and neurovascular bundle preservation during RALP, McClure et al. (2012) performed a prospective study of 105 consecutive men who underwent mpMRI with endorectal coil before RALP. In this study, two expert radiologists reviewed a preceding mpMRI before performance of RALP by a single expert surgeon. The surgeon was blinded to the finding on mpMRI and asked to formulate a plan based on other clinical variables. Following documentation of a blinded resection plan, MRI results were reviewed and a reevaluated resection plan based on MRI findings was documented. The primary endpoint was to evaluate the impact of preoperative mpMRI on the extent of surgical resection bilaterally, in light of the presurgery MRI review. The surgical plan was changed based on information from prostate mpMRI in $27 \%$ of cases reviewed. Among those who had a change in surgical plan, 59\% changed from non-nerve sparing to nerve sparing and $41 \%$ changed from nerve sparing to non-nerve sparing. Positive margins were found in seven patients, whereby six patients had an mpMRI that resulted in no change and one patient had a positive margin where mpMRI changed from non-nerve-sparing to a nerve-sparing technique. Overall, they concluded that a review of the prostate mpMRI led to patients undergoing less morbid surgery, which spared nerves, allowed for equal oncologic outcomes, and reduced overall positive surgical margin rate (McClure et al. 2012).

\section{MOLECULAR IMAGING IN PROSTATE CANCER}

Molecular imaging has been developed as a tool to better characterize and assess the various disease states of prostate cancer, but especially advanced disease. Although the following section reviews the roles of modern molecular imaging in prostate cancer management (see Fig. 2), it should be understood that current guidelines still recommend the use of conventional imaging, such as computed tomography (CT), during initial staging evaluation for prostate cancer (Mohler et al. 2016). With this being said, multiple molecular imaging technologies are currently in use or undergoing continued investigation and can be distributed into three basic categories: (1) bone matrix imaging, (2) markers of cellular metabolism, and (3) markers of prostate cancer-specific membrane proteins. These categories have been established based on knowledge of differential tumor biology and take advantage of aberrant physiological processes that arise as a result of the underlying malignancy (see Table 3).

\section{Anatomic Imaging and Bone Scintigraphy}

As described in earlier sections, anatomic imaging in prostate cancer is largely accomplished with TRUS and mpMRI. CT scans are currently accepted as the standard technique to assess pelvic lymphadenopathy and extraprostatic disease extension. However, given that the sensitivity for detection of nodal metastases using CT scan $\sim 35 \%$, much energy has gone toward developing imaging techniques that more accurately determine the presence of nodal and skeletal metastases.

The most common sites for prostate cancer metastases are the bones; therefore, imaging modalities that identify early metastatic bone deposits, typically osteoblastic and sclerotic, are required to accurately stage men with intermediate to high-risk prostate cancer. The current and most widely accepted modality to evaluate for the presence of distant bone metastases is "bone scintigraphy" (i.e., bone scans). Following injection of technetium-99m-labeled 
E.T. Miller et al.

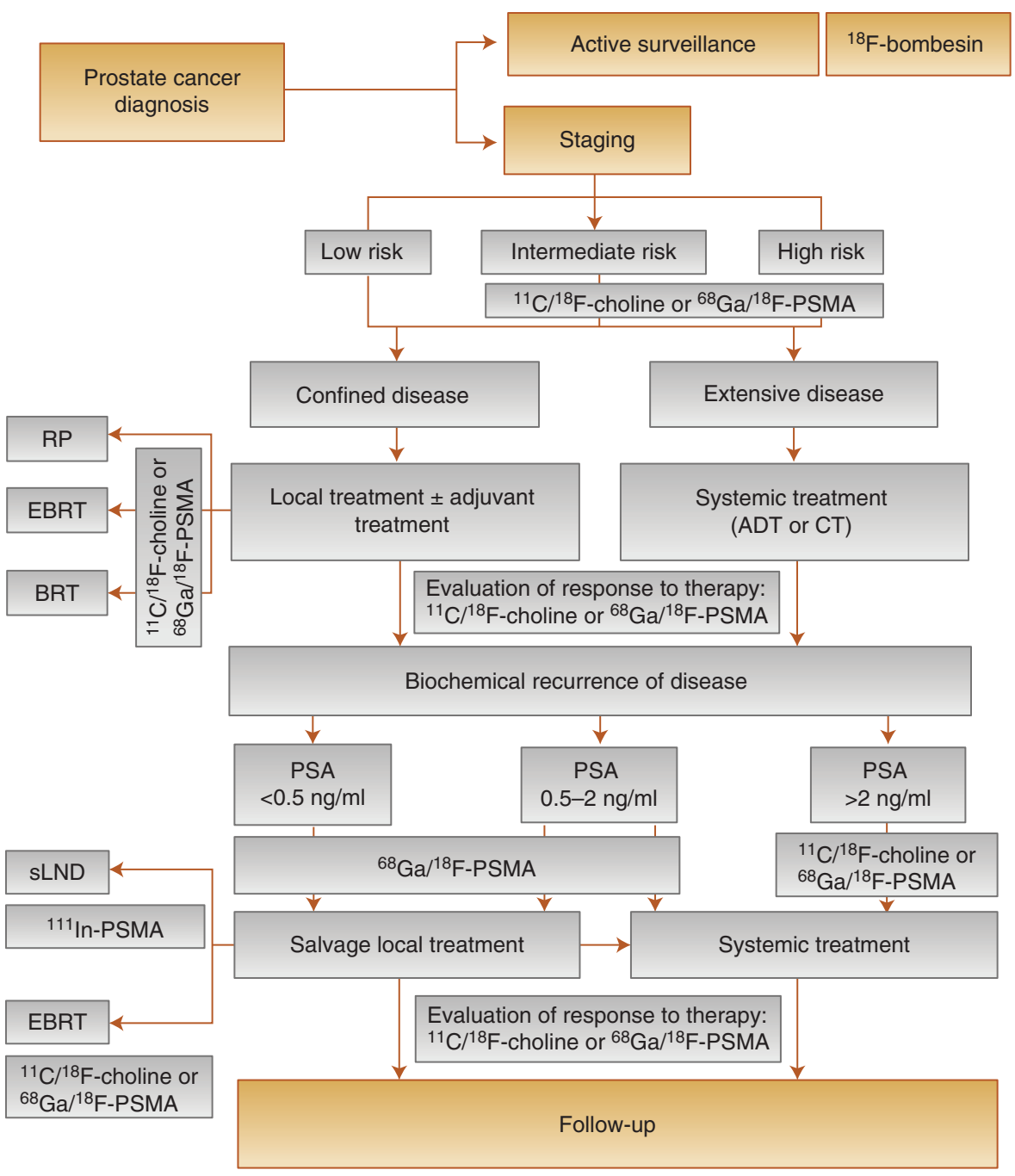

Figure 2. Flow-chart depicting the roles of molecular imaging in the diagnostic management of prostate cancer patients. ADT, Antiandrogen therapy; BRT, brachytherapy; CT, chemotherapy; EBRT, external beam radiotherapy; PSA, prostate-specific antigen; PSMA, prostate-specific membrane antigen; RP, radical prostatectomy; sLND, salvage lymphadenectomy; ${ }^{18} \mathrm{~F}$, fluorine-18; ${ }^{11} \mathrm{C}$, choline- $11 ;{ }^{68} \mathrm{Ga}$, gallium-68; ${ }^{111} \mathrm{In}$, indium-111. (From Evangelista et al. 2016; reprinted, with permission, from Elsevier, license 3904291180143.)

bisphosphonate $\left({ }^{99 \mathrm{~m}} \mathrm{Tc}-\mathrm{MDP}\right)$, a planar $\gamma$ camera scan is acquired and aims to detect ${ }^{99 m}$ Tc-MDP that has been incorporated into hydroxyapatite crystals and collagen matrix of active bone-remodeling sites (Ulmert et al. 2015). Unfortunately, bone scintigraphy is limited by poor sensitivities and specificities that are at best $70 \%$ and $75 \%$, respectively (EvenSapir et al. 2006; Minamimoto et al. 2015). A similar modality, known as single-photon emis- sion computed tomography (SPECT), is able to gather a volumetric distribution of the ${ }^{99 \mathrm{~m}} \mathrm{Tc}$ MDP tracer by rotating $\gamma$ detectors around the patient during image acquisition. When compared with conventional bone scintigraphy, SPECT has been proven to be statistically superior in regard to both sensitivity and specificity (Even-Sapir et al. 2006). Although bone scintigraphy is the current mainstay for staging and detection of skeletal metastases, techniques 
Imaging in Prostate Cancer

Table 3. The biological mechanisms behind molecular imaging in prostate cancer

\begin{tabular}{|c|c|c|c|c|}
\hline Agent & Target & Technique & Measured effect & Application \\
\hline${ }^{99 \mathrm{~m}} \mathrm{Tc}-\mathrm{MDP}$ & Hydroxyapatite & $\begin{array}{l}\text { Planar } \\
\text { scintigraphy/ } \\
\text { SPECT }\end{array}$ & Active bone remodeling & Bone metastasis \\
\hline${ }^{18} \mathrm{~F}-\mathrm{NaF}$ & Hydroxyapatite & PET & Active bone remodeling & Bone metastasis \\
\hline${ }^{18} \mathrm{~F}-\mathrm{FDG}$ & Glucose analog & PET & Glucose consumption & $\begin{array}{l}\text { Biochemical } \\
\text { recurrence }\end{array}$ \\
\hline${ }^{18} \mathrm{~F} /{ }^{11} \mathrm{C}$-acetate & Fatty acid synthase & PET & Fatty acid metabolism & $\begin{array}{l}\text { Biochemical } \\
\text { recurrence }\end{array}$ \\
\hline${ }^{18} \mathrm{~F} /{ }^{11} \mathrm{C}$-choline & Choline kinase & PET & Fatty acid metabolism & $\begin{array}{l}\text { Biochemical } \\
\text { recurrence }\end{array}$ \\
\hline $\begin{array}{l}{ }^{111} \text { In-capromab } \\
\text { pendetide }\end{array}$ & PSMA (antibody) & Planar scintigraphy & $\begin{array}{l}\text { Prostate cancer cell } \\
\text { surface protein }\end{array}$ & $\begin{array}{l}\text { Biochemical } \\
\text { recurrence }\end{array}$ \\
\hline${ }^{111}$ In-J591 & PSMA (antibody) & SPECT & $\begin{array}{l}\text { Prostate cancer cell } \\
\text { surface protein }\end{array}$ & $\begin{array}{l}\text { Biochemical } \\
\text { recurrence }\end{array}$ \\
\hline${ }^{68}$ Ga-PSMA & PSMA (urea-based) & PET & $\begin{array}{l}\text { Prostate cancer cell } \\
\text { surface protein }\end{array}$ & $\begin{array}{l}\text { Biochemical } \\
\text { recurrence }\end{array}$ \\
\hline${ }^{18} \mathrm{~F}-\mathrm{DCFPyL}$ & PSMA (urea-based) & PET & $\begin{array}{l}\text { Prostate cancer cell } \\
\text { surface protein }\end{array}$ & $\begin{array}{l}\text { Biochemical } \\
\text { recurrence }\end{array}$ \\
\hline${ }^{18} \mathrm{~F}-\mathrm{FACBC}$ & $\begin{array}{l}\text { L-leucine amino acid } \\
\text { analog }\end{array}$ & PET & $\begin{array}{l}\text { Amino acid transporters } \\
\text { in cancer cells }\end{array}$ & $\begin{array}{l}\text { Biochemical } \\
\text { recurrence }\end{array}$ \\
\hline
\end{tabular}

PET, Positron emission tomography; SPECT, single-photon emission computed tomography; PSMA, prostate-specific membrane antigen; MDP, methylene diphosphonate; NaF, ${ }^{18} \mathrm{~F}$-sodium fluoride; ${ }^{18} \mathrm{~F}$-FDG, ${ }^{18} \mathrm{~F}$-fluoro-D-glucose; ${ }^{18} \mathrm{~F}$ DCFPyL, 2-(3-(1-carboxy-5-[(6- $\left[{ }^{18} \mathrm{~F}\right]$ fluoro-pyridine-3-carbonyl)-amino]-pentyl)-ureido)-pentanedioic acid; ${ }^{18} \mathrm{~F}$-FACBC, ${ }^{18} \mathrm{~F}$-fluorocyclobutane-1-carboxylic acid; ${ }^{111} \mathrm{In}$, indium-111; ${ }^{99} \mathrm{Tc}$, technitium-99m; ${ }^{18} \mathrm{~F}$, fluorine- $18 ;{ }^{11} \mathrm{C}$, choline-11; ${ }^{68} \mathrm{Ga}$, gallium-68.

that incorporate positron emission tomography (PET) are promising methods that will likely displace other technologies.

\section{${ }^{18} \mathrm{~F}-\mathrm{NaF},{ }^{18} \mathrm{~F}-\mathrm{FDG},{ }^{11} \mathrm{C}-/{ }^{18} \mathrm{~F}$-Labeled Acetate and Choline PET Imaging}

PET represents an imaging technology that has been available for several decades. However, its use has been limited to a few specialized centers because of the cost of high-quality PET scanners in addition to the technical logistics that surround manufacture and delivery of radiopharmaceuticals. Currently, several radiotracers are widely studied and aim to better characterize primary tumor and prostate cancer staging. The four most widely studied radiotracers are ${ }^{18} \mathrm{~F}$-sodium fluoride $\left({ }^{18} \mathrm{~F}-\mathrm{NaF}\right),{ }^{18} \mathrm{~F}$-fluoro-Dglucose $\left({ }^{18} \mathrm{~F}-\mathrm{FDG}\right),{ }^{18} \mathrm{~F}$ - or ${ }^{11} \mathrm{C}$-labeled acetate, and ${ }^{18} \mathrm{~F}$ - or ${ }^{11} \mathrm{C}$-labeled choline.

The mechanism of action of ${ }^{18} \mathrm{~F}-\mathrm{NaF}$ is similar to that of methylene diphosphonate (MDP) used in standard bone scintigraphy. The ${ }^{18} \mathrm{~F}$ $\mathrm{NaF}$ radiotracer colocalizes to skeletal regions with increased blood flow and active bone remodeling, thus its use is optimized in the setting of staging and identification of early osseous metastases. The hybridization of PET imaging, along with the morphological features acquired from CT scans, allows for improved specificity in distinguishing between benign degenerative changes and true functional malignant processes (Even-Sapir et al. 2006; Segall et al. 2010). Image quality is enhanced over standard bone scintigraphy as is bone uptake, radiotracer clearance, radiation dose, and time from injection to imaging ( $\mathrm{Li}$ et al. 2012). ${ }^{18} \mathrm{~F}-\mathrm{NaF}$ is especially useful in prostate cancer because it is most sensitive in the detection of osteoblastic lesions. Multiple studies have shown that the sensitivity of ${ }^{18}$ F-NaF PET reliably approaches $100 \%$. Without morphological characteristics of the CT scan, ${ }^{18} \mathrm{~F}-\mathrm{NaF}$ PET imaging has a specificity of $\sim 62 \%$ to $72 \%$; however, with the ad- 
E.T. Miller et al.

dition of hybridized CT/PET images, specificity can approach $97 \%$ to $100 \%$ (Even-Sapir et al. 2006; Tateishi et al. 2010; Li et al. 2012).

As a tool to detect osseous metastases, ${ }^{18} \mathrm{~F}$ $\mathrm{NaF}$ PET/CT imaging has been shown to be more sensitive and specific when compared with planar bone scintigraphy and SPECT imaging (Even-Sapir et al. 2006). In relation, a recent study evaluating the impact of ${ }^{18} \mathrm{~F}-\mathrm{NaF}$ PET in prostate cancer management determined that the use of ${ }^{18} \mathrm{~F}-\mathrm{NaF}$ PET has a high impact on management, especially in relation to replacing other advanced imaging modalities (Hillner et al. 2014). Although ${ }^{18} \mathrm{~F}-\mathrm{NaF}$ PET imaging achieves near perfect sensitivity and specificity in the detection of distant bone metastases, it lacks the ability to detect primary tumors and local lymph node spread. Thus, other radioisotopes have been studied extensively with regard to detection of primary cancer and nodal disease.

${ }^{18}$ F-FDG PET scans are based on the Warburg effect, whereby malignant cells with increased glucose metabolism are detected as a result of increased uptake of the FDG radiotracer (Smith 2000; Macheda et al. 2005). Although ${ }^{18}$ F-FDG PET imaging has proven usefulness in other malignancies, the underlying mechanism of ${ }^{18} \mathrm{~F}$-FDG is problematic in primary prostate cancer because detection is limited by coaccumulation of the radiotracer in $\mathrm{BPH}$ and normal prostate tissue (Salminen et al. 2002). Furthermore, a high level of ${ }^{18} \mathrm{~F}-\mathrm{FDG}$ radiotracer buildup in the urinary bladder makes detection of primary prostate cancer almost impossible (Liu et al. 2001). Despite these limitations, when compared with well-differentiated, localized, and low-PSA-producing tumors, some have found increased ${ }^{18} \mathrm{~F}$-FDG uptake in tumors with higher PSA and poorly differentiated regions (Oyama et al. 1999).

${ }^{18}$ F-FDG PET has also been studied in the setting of PSA relapse following definitive treatment with radiation therapy or radical prostatectomy. In a study by Chang et al. (2003), 24 men who had undergone curative-intent treatment were evaluated with ${ }^{18} \mathrm{~F}$-FDG PET before pelvic lymph node dissection. The investigators concluded that ${ }^{18}$ F-FDG PET may be useful to detect pelvic lymph metastases, whereby the sensitivity and specificity of detecting metastatic lymph nodes was $75 \%$ and $100 \%$, respectively (Chang et al. 2003). By comparison, Schöder et al. (2005) found a $31 \%$ rate of true positive local or systemic disease in patients with PSA relapse. To date, conclusions about the ability to distinguish local or systemic disease with ${ }^{18} \mathrm{~F}$ FDG PETare limited by study heterogeneity and varied validation criteria across studies.

Acetate- and choline-based PET imaging takes advantage of an increase in malignancyinduced cell-membrane synthesis, which subsequently leads to increased trapping of both acetate and choline substrates. With an up-regulation in fatty acid synthase in prostate tumor cells, ${ }^{18} \mathrm{~F}$ - or ${ }^{11} \mathrm{C}$-labeled acetate is incorporated into cellular membranes and neutral lipids in the form of phosphatidylcholine. By comparison, up-regulation of choline kinase leads to incorporation of ${ }^{18} \mathrm{~F}$ - or ${ }^{11} \mathrm{C}$-labeled choline into tumor cellular membranes, also in the form of phosphatidylcholine (Jadvar 2013).

In contrast to the aforementioned limitations related to ${ }^{18} \mathrm{~F}$-FDG, ${ }^{11} \mathrm{C}$-acetate has minimal accumulation in the urinary bladder, which allows for optimal evaluation of the prostate bed during functional scanning. In a study by Oyama et al. (2003), a comparison between ${ }^{18} \mathrm{~F}$-FDG and ${ }^{11} \mathrm{C}$-acetate showed that ${ }^{11} \mathrm{C}$-acetate was more sensitive in the detection of primary prostate cancer. The use of ${ }^{11} \mathrm{C}$-acetate in disease recurrence and restaging has also been studied. A preliminary study by Kotzerke et al. (2002) showed a relatively high sensitivity and specificity in the diagnosis of recurrent prostate cancer, independent of PSAvalue. Other groups have shown similar sensitivities and specificities in relation to recurrent disease, but further studies are needed to establish acceptable criteria that describe the use and effectiveness of ${ }^{11} \mathrm{C}$ acetate PET/CT (Oyama et al. 2003; Sandblom et al. 2006).

Many investigators evaluating the role of ${ }^{11} \mathrm{C}$-choline PET/CT in the diagnosis of primary prostate cancer have focused on comparing the benefits of ${ }^{11} \mathrm{C}$-choline PET to MRI. Some reports have shown that ${ }^{11} \mathrm{C}$-choline PET has superior sensitivity for detection of primary 
prostate tumor when compared with MRI. In a study comparing prebiopsy imaging to final biopsy pathology, Yamaguchi et al. (2005) report a diagnostic sensitivity for prostate cancer of $100 \%$, whereas MRI and MRSI were $60 \%$ and $65 \%$, respectively. A separate study showed the sensitivity and specificity of ${ }^{11} \mathrm{C}$-choline PET/ CT of $55 \%$ and $86 \%$, respectively, which was similar to MRI sensitivity and specificity of $81 \%$ and $67 \%$, respectively (Testa et al. 2007). To investigate the specificity of ${ }^{11} \mathrm{C}$-choline PET, Scher et al. (2007) performed ${ }^{11}$ C-choline PET/ CT in 58 patients who later underwent prostate biopsy or radical prostatectomy. Prevalence of prostate cancer in their selected cohort was 63.8\%, whereby ${ }^{11} \mathrm{C}$-choline PET/CT revealed a sensitivity and specificity of $86.5 \%$ and $61.9 \%$, respectively (Scher et al. 2007).

The role of ${ }^{11} \mathrm{C}$-choline $\mathrm{PET}$ imaging in lymph node staging among intermediate and high-risk disease is also an important area of study. Schiavina et al. (2008) compared ${ }^{11} \mathrm{C}$ choline PET/CT with clinical nomograms and despite a rather low sensitivity of $60 \%,{ }^{11} \mathrm{C}$-choline PET/CT performed with equal sensitivity and improved specificity. Most importantly, however, it appeared that tumor deposit size was an important limiting factor, which was expected given the poor spatial resolution of $\mathrm{PET} / \mathrm{CT}$ for lesions $<4-5 \mathrm{~mm}$ (Schiavina et al. 2008).

The ability to detect recurrent disease with ${ }^{11} \mathrm{C}$-choline PET has been studied extensively. In a study by Reske et al. (2008), men with evidence of biochemical relapse after radical prostatectomy underwent ${ }^{11} \mathrm{C}$-choline PET/CT. The sensitivity and specificity of ${ }^{11} \mathrm{C}$-choline PET/ $\mathrm{CT}$ in the detection of local recurrence was reported as $73 \%$ and $88 \%$, respectively (Reske et al. 2008). In a separate study, the sensitivity of detecting local recurrence after prostatectomy was much lower at $38 \%$, whereas the sensitivity in a comparable cohort of men who underwent primary-only radiation therapy was 78\% (de Jong et al. 2003). Thus, a more prevalent adoption of ${ }^{11} \mathrm{C}$-choline PET in the detection of disease recurrence is currently limited by low sensitivities and the ability to reproduce comparable sensitivities in validation studies.

\section{Anti- ${ }^{18}$ F-FACBC PET Imaging}

An agent known as anti-1-amino-3-[ $\left.{ }^{18} \mathrm{~F}\right]$ fluorocyclobutane-1-carboxylic acid (anti-18FFACBC) is a synthetic analog of the amino acid leucine. The mechanism behind anti-18FFACBC relies on increased activity of the alanine-serine-cysteine (ASC) transport system, which then leads to an increased accumulation of the anti-18F-FACBC radiotracer in cells with ASC system up-regulation (Oka et al. 2012). When paired with PET/CT scanning, this investigational radionuclide has the potential to optimize detection of recurrent prostate cancer with relatively high accuracy. A recent metaanalysis evaluating the role of ${ }^{18} \mathrm{~F}$-FACBC-PET in the diagnosis of recurrent prostate cancer found a pooled sensitivity of $87 \%$, pooled specificity of $66 \%$, and 0.93 the area under the receiver-operating characteristic curve in detecting prostate cancer recurrence (Ren et al. 2016). The noted advantage of ${ }^{18} \mathrm{~F}-\mathrm{FACBC}$ is more favorable distribution in the body compared with other PET radiotracers, especially with regard to limited accumulation in the urinary tract (Nanni et al. 2013). Furthermore, a long half-life and short synthesis time makes manufacture possible in the absence of an onsite cyclotron (McConathy et al. 2003). Unfortunately, the mechanism of action is not specific to prostate cancer and studies have found increased uptake of ${ }^{18} \mathrm{~F}$-FACBC in nonmalignant tissue as well (Schuster et al. 2011, 2014). This finding is a fundamental reason why false positives remain problematic and thus raise concern over the ability to improve specificity to an acceptable standard that would make 18FFACBC superior to other modalities.

\section{AN EMERGING MOLECULAR TARGET}

\section{Prostate-Specific Membrane Antigen-Based PET Imaging}

The molecular targets of previously discussed PET-imaging modalities, including choline, acetate, fluoride, and FDG are not entirely prostate cancer specific. In other words, these modalities provide information about a micro- 
E.T. Miller et al.

environment that is altered as a result of the presence of prostate cancer and do not necessarily represent underlying tumor-specific molecular changes that occur within malignant cells. For this reason, achieving adequate and reproducible diagnostic specificities with the aforementioned PET-imaging modalities has been recognized as a major challenge. With a primary goal to improve and optimize specificity, the remaining modality discussed herein hones in on an antigen and molecular pathway that are active in the various disease states of prostate cancer. This widely studied mechanism relies on an enzyme known as prostate-specific membrane antigen (PSMA).

PSMA is a multifunctional zinc protease enzyme that has markedly increased expression in most prostate cancer cells; whereas, expression in benign prostate tissue is almost completely absent (Leek et al. 1995; Silver et al. 1997; Eder et al. 2014). The genotype and structure of PSMA is well characterized, as are cancer-specific ligands that interact with PSMA and later become internalized at time of binding (Maurer et al. 2016). Knowledge of this protein-ligand interaction has directed development of radionuclide complexes that can be used in the realm of both therapeutic and imaging studies (socalled theranostics).

As a carcinoma-specific imaging target, PSMA is a transmembrane protein that has been studied extensively with resultant development of multiple agents that target multiple domains and functionalities. The first of these agents is the capromab pendetide antibody (ProstaScint). This antibody is used with planar scintigraphy and has been investigated in the identification of extraprostatic disease and the improvement of staging accuracy. Despite its FDA approval, the ProstaScint antibody has many known limitations (Taneja 2004; Bander 2006). First, it targets an intracellular region of the transmembrane protein and several investigators have questioned its ability to bind to viable cells in vivo (Liu et al. 1997). Second, as with all scintigraphy scans, ProstaScint scanning has relatively low spatial resolution, which must be optimized by complex image-acquisition protocols that are designed to take place over several days. Finally, given its long half-life, the

${ }^{111}$ In radioisotope used in ProstaScint scanning contributes to a much higher dose of radiation when compared with other PET imaging modalities (Afshar-Oromieh et al. 2013). Secondgeneration monoclonal antibodies, such as the anti-J591 antibody, have aimed to improve some of these limitations by targeting the extracellular domain of PSMA in viable tumor cells. Although clinical trials have shown improved image contrast, anti-J591 antibodies are marked by the same limitations, such as increased background activity, prolonged radiotracer circulation, and higher radiation doses to nontarget organs (Tagawa et al. 2010). Given these notable limitations, further studies have focused on radioisotope-labeled ligands that bind to the enzymatic pockets of PSMA, allowing for use with PET/CT imaging modalities.

Improved characterization of PSMA substrate recognition sites has allowed for the production of small molecule inhibitors or ligands that bind to and interact with the PSMA protein (Luthi-Carter et al. 1998; Tiffany et al. 1999). The three basic categories of small molecule PSMA inhibitors are: (1) urea-based, (2) thiol-based, and (3) phosphorous-based. Data originating from LNCaP cell line studies have revealed that urea-based inhibitors have a significantly higher affinity and specificity for the PSMA protein; therefore, the majority of current research has focused on engineering inhibitors that rely on the urea-based ligand interactions (Eder et al. 2012).

The most common agent used in PET imaging relies on a urea-based small molecule inhibitor called Glu-NH-CO-NH-Lys(Ahx)HBED-CC or ${ }^{68}$ Ga-PSMA-HBED-CC. The benefits of ${ }^{68} \mathrm{Ga}-P S M A-H B E D-C C$ include high accumulation at prostate cancer metastases, low uptake in the retroperitoneum, bone, and benign lymph nodes, ease of production, thermodynamic stability, fast blood and organ clearance, high specificity for PSMA-expressing tissue, and limited accumulation in the liver (Eder et al. 2012; Afshar-Oromieh et al. 2013). Several other potential PSMA agents are currently being investigated, some of which include Euk-Subkff- ${ }^{68}$ Ga-DOTAGA (Weineisen et al. 
2014), ${ }^{68}$ Ga-PSMA-617 (Benesova et al. 2015), and ${ }^{18}$ F-DCFPyL (Chen et al. 2011). In general, further preclinical and clinical studies involving these experimental "theranostic" agents are needed to clarify safety profiles, tissue specificity, and metabolic clearance mechanisms. Fortunately, ${ }^{68} \mathrm{Ga}-\mathrm{PSMA}-\mathrm{HBED}-\mathrm{CC}$ PET (i.e., ${ }^{68} \mathrm{Ga}$-PSMA-PET) has been studied extensively across the disease states of prostate cancer including high-risk disease, disease recurrence, and for monitoring patients who are undergoing ongoing therapy.

As discussed in prior sections of this review, clinical staging with cross-sectional CT-scans, MRI imaging, and/or other PET radiotracers remains rather susceptible to poor detection accuracy. When combined with the anatomic and functional sequences of mpMRI, coregistration with whole-body PET scanning can add an additional level of potentially impactful molecular information (Souvatzoglou et al. 2013). Although the usage of PSMA-PET imaging in the diagnosis of primary prostate cancer is still far from established (Storz et al. 2015), its use in high-risk disease, particularly lymph node staging, is an area of intense study. An expanded understanding of the benefits and drawbacks of PSMA-PET imaging may help supplant the limitations and vulnerabilities of our current modalities, thus many studies have been performed with this concern in mind. In a study by Budaus et al. (2016), ${ }^{68}$ Ga-PSMA-PET/CT was assessed to determine the accuracy of lymph node staging in high-risk patients before radical prostatectomy. When using final resection histopathology as the reference standard, they concluded that ${ }^{68} \mathrm{Ga}$-PSMA PET/CT was limited in its ability to detect smaller lymph node metastases. The median size of ${ }^{68} \mathrm{Ga}-\mathrm{PSMA}$ PET/CT detected metastases was $13.6 \mathrm{~mm}$, which was significantly different than the $4.3 \mathrm{~mm}$ metastases that went undetected. Although the specificity and positive predictive values were $100 \%$, the measured sensitivity was a mere $33.3 \%$. Despite these findings, the investigators still supported the notion that PSMA-PET imaging is a promising technique and may require refinement with PSMA ligands such as ${ }^{68} \mathrm{Ga}$ BAY86-7548 or ${ }^{89}$ Zr-Df-IAB2 M (Budaus et al.
2016). Other investigators have recommended scenarios that combine ${ }^{68} \mathrm{Ga}$-PSMA PET imaging with cross-sectional MRI (i.e., ${ }^{68} \mathrm{Ga}$-PSMA PET/MRI), which would essentially take advantage of the best sensitivities and specificities of the combined modalities (Maurer et al. 2014). Clearly, further systematic and prospective trials are needed to optimize PSMA-PET use in the setting of high-risk prostate cancer.

Most importantly, ${ }^{68}$ Ga-PSMA-PET appears especially effective as an agent to detect recurrent prostate cancer (Afshar-Oromieh et al. 2014; Maurer et al. 2016). In a retrospective analysis by Afshar-Oromieh et al. (2015), following definitive treatment with prostatectomy or radiation therapy, 319 patients underwent ${ }^{68}$ GA-PSMA-PET/CT to determine accuracy of detection for recurrent disease. Median PSA in men with recurrent disease was $4.6 \mathrm{ng} / \mathrm{ml}$. Approximately $83 \%$ of patients had at least one lesion concerning prostate cancer on ${ }^{68} \mathrm{Ga}$-PSMA PET scans, indicating that ${ }^{68} \mathrm{Ga}$ PSMA PET imaging may detect a high percentage of patients with suspected recurrent cancer. On multivariable analysis, there was no association with Gleason scores, PSA doubling times, and/or treatment with androgen-deprivation therapy. However, detection of prostate cancer was increased when PSA levels were more highly elevated. Histological assessment was possible in 42 patients with positive scans, which led to a calculated sensitivity of $76 \%$ and specificity of $100 \%$ (Afshar-Oromieh et al. 2015). In a comparable analysis by Eiber et al. (2015), 248 patients who had previously underwent radical prostatectomy were scanned with ${ }^{68} \mathrm{Ga}$-PSMA$\mathrm{PET} / \mathrm{CT}$ imaging at time of biochemical recurrence. In this cohort, median PSA was $1.99 \mathrm{ng} /$ $\mathrm{mL}$ and the rate detection of suspicious lesions was $89.5 \%$. Similar to the Afshar-Oromieh et al. (2015) study, increased detection rates were associated with higher serum PSA values (detection rates of $57.9 \%, 72.7 \%, 93.0 \%$, and $96.8 \%$ were associated with PSA values of 0.2 to $<0.5 \mathrm{ng} / \mathrm{ml}, 0.5$ to $<1 \mathrm{ng} / \mathrm{ml}, 1$ to $<2 \mathrm{ng} / \mathrm{ml}$, and $\geq 2 \mathrm{ng} / \mathrm{ml}$, respectively) (Eiber et al. 2015). Studies like these, in addition to other ongoing trials, have begun to show that ${ }^{68} \mathrm{Ga}$-PSMA-PET imaging is a potentially powerful tool with an 
E.T. Miller et al.

ability to accurately detect recurrent prostate cancer (Dietlein et al. 2015). At this point, the most proven indication for PSMA-PET imaging lies within the state of recurrent disease. With further optimization, the use of PSMA-PET imaging will likely detect recurrent lesions with high accuracy, which will ultimately guide more effective adjuvant and salvage therapies.

A final disease state in which PSMA-PET imaging may show extreme value is in the management of patients with both hormonesensitive and castrate-resistant bone metastatic disease. Based on studies that have examined planar bone scintigraphy and cross-sectional CT scans, PSMA-PET imaging appears to have a superior detection efficacy for bone metastatic prostate cancer (Rowe et al. 2016). In light of these findings, if PSMA-PET imaging studies were further refined and optimized, specifically with the ability to detect bone metastases, there would be many potential benefits. It would allow physicians to monitor treatment response in patients who have received bone-seeking pharmaceuticals, such as ${ }^{223} \mathrm{Ra}$ dichloride (Colletti 2013). Focal treatment and accurate follow-up in patients with so-called oligometastatic prostate cancer may be possible and proven effective (Reyes and Pienta 2015). Finally, the development of PSMA-based ligands and small molecular inhibitors that participate in both imaging and therapeutic trials would allow for optimal theranostic strategies that target patients with otherwise few treatment options. As an example, phase I and phase II studies investigating the radiotherapeutic usage of ${ }^{177} \mathrm{Lu}$-J591 anti-PSMA antibody in the treatment of progressive metastatic castrate resistant prostate cancer have revealed that the anti-J591-based agent was well tolerated, was taken up at metastatic sites, and resulted in a measurable decrease in PSA (Bander et al. 2005; Tagawa et al. 2013). Further studies evaluating the long-term toxicity to nontarget organs with high radiotracer uptake (i.e., kidneys and salivary glands) are needed to ensure that newly engineered theranostic agents, which target diffuse metastatic disease, are safe.

\section{CONCLUDING REMARKS}

This review has outlined the most highly studied imaging modalities that exist within prostate cancer management. Although far from exhaustive, it introduces key studies that have shown the potential feasibility of new and emerging technologies and techniques. It should be noted that the ranges of reported sensitivities and specificities are quite broad. In general, the ability to accurately detect primary disease, lymph node metastases, local recurrence, or distant metastatic spread with imaging is likely dependent on factors, including PSA, Gleason score, pathological stage, tumor size, primary or ongoing treatments, as well as other currently undetermined factors. Furthermore, many agents, especially PSMA-based agents, are largely experimental with use that is restricted to only a few select centers. This broad range of accuracies, as well as the enacted restrictions, is a strong reminder that further studies are needed to determine which factors, if any, will maximize the use and safety of different imaging across the prostate cancer disease states.

\section{REFERENCES}

Abd-Alazeez M, Kirkham A, Ahmed HU, Arya M, Anastasiadis E, Charman SC, Freeman A, Emberton M. 2014. Performance of multiparametric MRI in men at risk of prostate cancer before the first biopsy: A paired validating cohort study using template prostate mapping biopsies as the reference standard. Prostate Cancer Prostatic Dis 17: 40-46.

Afshar-Oromieh A, Malcher A, Eder M, Eisenhut M, Linhart HG, Hadaschik BA, Holland-Letz T, Giesel FL, Kratochwil C, Haufe S, et al. 2013. PET imaging with a $\left[{ }^{68} \mathrm{Ga}\right]$ gallium-labelled PSMA ligand for the diagnosis of prostate cancer: Biodistribution in humans and first evaluation of tumour lesions. Eur J Nucl Med Mol Imaging 40: 486-495.

Afshar-Oromieh A, Haberkorn U, Schlemmer HP, Fenchel M, Eder M, Eisenhut M, Hadaschik BA, KoppSchneider A, Rothke M. 2014. Comparison of PET/ CT and PET/MRI hybrid systems using a ${ }^{68} \mathrm{Ga}$-labelled PSMA ligand for the diagnosis of recurrent prostate cancer: Initial experience. Eur J Nucl Med Mol Imaging 41: $887-897$.

Afshar-Oromieh A, Avtzi E, Giesel FL, Holland-Letz T, Linhart HG, Eder M, Eisenhut M, Boxler S, Hadaschik BA, Kratochwil C, et al. 2015. The diagnostic value of PET/ $\mathrm{CT}$ imaging with the ${ }^{68} \mathrm{Ga}$-labelled PSMA ligand HBED$\mathrm{CC}$ in the diagnosis of recurrent prostate cancer. Eur J Nucl Med Mol Imaging 42: 197-209. 
Ashley RA, Inman BA, Routh JC, Mynderse LA, Gettman MT, Blute ML. 2008. Reassessing the diagnostic yield of saturation biopsy of the prostate. Eur Urol 53: 976-983.

Bander NH. 2006. Technology Insight: Monoclonal antibody imaging of prostate cancer. Nat Clin Pract Urol 3: 216-225.

Bander NH, Milowsky MI, Nanus DM, Kostakoglu L, Vallabhajosula S, Goldsmith SJ. 2005. Phase I trial of ${ }^{177}$ lutetium-labeled J591, a monoclonal antibody to prostate-specific membrane antigen, in patients with androgen-independent prostate cancer. J Clin Oncol 23: 4591-4601.

Barentsz JO, Richenberg J, Clements R, Choyke P, Verma S, Villeirs G, Rouviere O, Logager V, Fütterer JJ. 2012. ESUR prostate MR guidelines 2012. Eur Radiol 22: 746-757.

Benesova M, Schafer M, Bauder-Wust U, Afshar-Oromieh A, Kratochwil C, Mier W, Haberkorn U, Kopka K, Eder M. 2015. Preclinical evaluation of a tailor-made DOTAconjugated PSMA inhibitor with optimized linker moiety for imaging and endoradiotherapy of prostate cancer. J Nucl Med 56: 914-920.

Beyersdorff D, Taymoorian K, Knösel T, Schnorr D, Felix R, Hamm B, Bruhn H. 2005. MRI of prostate cancer at 1.5 and 3.0 T: Comparison of image quality in tumor detection and staging. Am J Roentgenol 185: 1214-1220.

Bhavsar A, Verma S. 2014. Anatomic imaging of the prostate. BioMed Res Intl 2014: 728539.

Bill-Axelson A, Holmberg L, Garmo H, Rider JR, Taari K, Busch C, Nordling S, Häggman M, Andersson SO, Spångberg A, et al. 2014. Radical prostatectomy or watchful waiting in early prostate cancer. $N$ Engl J Med 370: 932-942.

Bockholt N, Marks LS. 2015. Targeted prostate biopsy using magnetic resonance imaging-ultrasound fusion. Asian J Androl 17: 870-873.

Bolton DM, Ta A, Bagnato M, Muller D, Lawrentschuk NL, Severi G, Syme RR, Giles GG. 2014. Interval to biochemical recurrence following radical prostatectomy does not affect survival in men with low-risk prostate cancer. World J Urol 32: 431-435.

Box GN, Ahlering TE. 2008. Robotic radical prostatectomy: Long-term outcomes. Curr Opin Urol 18: 173-179.

Braeckman J, Autier P, Soviany C, Nir R, Nir D, Michielsen D, Treurnicht K, Jarmulowicz M, Bleiberg H, Govindaraju S, et al. 2008. The accuracy of transrectal ultrasonography supplemented with computer-aided ultrasonography for detecting small prostate cancers. BJU Int 102: $1560-1565$.

Brock M, von Bodman C, Sommerer F, Löppenberg B, Klein T, Deix T, Palisaar JR, Noldus J, Eggert T. 2011. Comparison of real-time elastography with grey-scale ultrasonography for detection of organ-confined prostate cancer and extra capsular extension: A prospective analysis using whole mount sections after radical prostatectomy. BJU Int 108: E217-E222.

Budaus L, Leyh-Bannurah SR, Salomon G, Michl U, Heinzer H, Huland H, Graefen M, Steuber T, Rosenbaum C. 2016. Initial experience of ${ }^{68} \mathrm{Ga}$-PSMA PET/CT imaging in high-risk prostate cancer patients prior to radical prostatectomy. Eur Urol 69: 393-396.

Carter HB, Albertsen PC, Barry MJ, Etzioni R, Freedland SJ, Greene KL, Holmberg L, Kantoff P, Konety BR, Murad
$\mathrm{MH}$, et al. 2013. Early detection of prostate cancer: AUA guideline. J Urol 190: 419-426.

Chamie K, Sonn GA, Finley DS, Tan N, Margolis DJA, Raman SS, Natarajan S, Huang J, Reiter RE. 2014. The role of magnetic resonance imaging in delineating clinically significant prostate cancer. Urology 83: 369-375.

Chang CH, Wu HC, Tsai JJP, Shen YY, Changlai SP, Kao A. 2003. Detecting metastatic pelvic lymph nodes by ${ }^{18} \mathrm{~F}-2$ deoxyglucose positron emission tomography in patients with prostate-specific antigen relapse after treatment for localized prostate cancer. Urol Int 70: 311-315.

Chen Y, Pullambhatla M, Foss CA, Byun Y, Nimmagadda S, Senthamizhchelvan S, Sgouros G, Mease RC, Pomper MG. 2011.2-(3-\{1-Carboxy-5- $\left[\left(6-\left[{ }^{18} \mathrm{~F}\right]\right.\right.$ fluoro-pyridine3-carbonyl)-amino]-pentyl\}-ureido)-pen tanedioic acid, $\left[{ }^{18} \mathrm{~F}\right]$ DCFPyL, a PSMA-based PET imaging agent for prostate cancer. Clin Cancer Res 17: 7645-7653.

Chon CH, Lai FC, McNeal JE, Presti JC Jr. 2002. Use of extended systematic sampling in patients with a prior negative prostate needle biopsy. J Urol 167: 2457-2460.

Colletti PM. 2013. New treatment option: ${ }^{223}$ Ra chloride, the first approved unsealed $\alpha$-emitting radiopharmaceutical. Clin Nuclear Med 38: 724-725.

Comet-Batlle J, Vilanova-Busquets JC, Saladié-Roig JM, Gelabert-Mas A, Barceló-Vidal C. 2003. The value of endorectal MRI in the early diagnosis of prostate cancer. Eur Urol 44: 201-208.

Cool DW, Zhang X, Romagnoli C, Izawa JI, Romano WM, Fenster A. 2014. Evaluation of MRI-TRUS fusion versus cognitive registration accuracy for MRI-targeted, TRUSguided prostate biopsy. Am J Roentgenol 204: 83-91.

Cooperberg MR, Pasta DJ, Elkin EP, Litwin MS, Latini DM, Du Chane J, Carroll PR. 2005. The University of California, San Francisco Cancer of the Prostate Risk Assessment score: A straightforward and reliable preoperative predictor of disease recurrence after radical prostatectomy. J Urol 173: 1938-1942.

Cooperberg MR, Broering JM, Kantoff PW, Carroll PR. 2007. Contemporary trends in low risk prostate cancer: Risk assessment and treatment. J Urol 178: S14-S19.

D'Amico AV, Whittington R, Malkowicz SB, Schultz D, Blank K, Broderick GA, Tomaszewski JE, Renshaw AA, Kaplan I, Beard CJ, et al. 1998. Biochemical outcome after radical prostatectomy, external beam radiation therapy, or interstitial radiation therapy for clinically localized prostate cancer. JAMA 280: 969-974.

de Jong IJ, Pruim J, Elsinga PH, Vaalburg W, Mensink HJ. 2003. ${ }^{11} \mathrm{C}$-choline positron emission tomography for the evaluation after treatment of localized prostate cancer. Eur Urol 44: 32-38; discussion 38-39.

Dietlein M, Kobe C, Kuhnert G, Stockter S, Fischer T, Schomacker K, Schmidt M, Dietlein F, Zlatopolskiy BD, Krapf $\mathrm{P}$, et al. 2015. Comparison of $\left[{ }^{18} \mathrm{~F}\right] \mathrm{DCFPyL}$ and $\left[{ }^{68} \mathrm{Ga}\right] \mathrm{Ga}$-PSMA-HBED-CC for PSMA-PET Imaging in patients with relapsed prostate cancer. Mol Imag Biol 17: 575-584.

Eder M, Schafer M, Bauder-Wust U, Hull WE, Wangler C, Mier W, Haberkorn U, Eisenhut M. 2012. ${ }^{68} \mathrm{Ga}$-complex lipophilicity and the targeting property of a urea-based PSMA inhibitor for PET imaging. Bioconjugate Chem 23: $688-697$. 
E.T. Miller et al.

Eder M, Neels O, Müller M, Bauder-Wüst U, Remde Y, Schäfer M, Hennrich U, Eisenhut M, Afshar-Oromieh A, Haberkorn U, et al. 2014. Novel preclinical and radiopharmaceutical aspects of $\left[{ }^{68} \mathrm{Ga}\right] \mathrm{Ga}-\mathrm{PSMA}-\mathrm{HBED}-\mathrm{CC}$ : A new PET tracer for imaging of prostate cancer. Pharmaceuticals 7: 779-796.

Eiber M, Maurer T, Souvatzoglou M, Beer AJ, Ruffani A, Haller B, Graner FP, Kubler H, Haberhorn U, Eisenhut M, et al. 2015. Evaluation of hybrid ${ }^{68}$ Ga-PSMA ligand PET/ CT in 248 patients with biochemical recurrence after radical prostatectomy. J Nucl Med 56: 668-674.

Eichler K, Hempel S, Wilby J, Myers L, Bachmann LM, Kleijnen J. 2006. Diagnostic value of systematic biopsy methods in the investigation of prostate cancer: A systematic review. J Urol 175: 1605-1612.

Engelhard K, Hollenbach HP, Kiefer B, Winkel A, Goeb K, Engehausen D. 2006. Prostate biopsy in the supine posi tion in a standard 1.5-T scanner under real time MR-imaging control using a MR-compatible endorectal biopsy device. Eur Radiol 16: 1237-1243.

Epstein JI, Walsh PC, Carmichael M, Brendler CB. 1994 Pathologic and clinical findings to predict tumor extent of nonpalpable (stage T1c) prostate cancer. JAMA 271: $368-374$.

Eskew LA, Bare RL, McCullough DL. 1997. Systematic 5 region prostate biopsy is superior to sextant method for diagnosing carcinoma of the prostate. J Urol 157: 199_ 202; discussion 202-193.

Evangelista L, Briganti A, Fanti S, Joniau S, Reske S, Schiavina R, Stief C, Thalmann GN, Picchio M. 2016. New clinical indications for ${ }^{18} \mathrm{~F} /{ }^{11} \mathrm{C}$-choline, new tracers for positron emission tomography and a promising hybrid device for prostate cancer staging: A systematic review of the literature. Eur Urol 70: 161-175.

Even-Sapir E, Metser U, Mishani E, Lievshitz G, Lerman H, Leibovitch I. 2006. The detection of bone metastases in patients with high-risk prostate cancer: ${ }^{99 \mathrm{~m}} \mathrm{Tc}-\mathrm{MDP}$ planar bone scintigraphy, single- and multi-field-of-view SPECT, ${ }^{18} \mathrm{~F}$-fluoride PET, and ${ }^{18} \mathrm{~F}$-fluoride PET/CT. $J$ Nucl Med 47: 287-297.

Felker ER, Margolis DJ, Nassiri N, Marks LS. 2016. Prostate cancer risk stratification with magnetic resonance imaging. Urol Oncol 34: 311-319.

Filson CP, Natarajan S, Margolis DJA, Huang J, Lieu P, Dorey FJ, Reiter RE, Marks LS. 2016. Prostate cancer detection with magnetic resonance-ultrasound fusion biopsy: The role of systematic and targeted biopsies. Cancer 122: 884-892.

Fischer S, Lin D, Simon RM, Howard LE, Aronson WJ, Terris MK, Kane CJ, Amling CL, Cooperberg MR, Freedland SJ, et al. 2016. Do all men with pathological Gleason score 8-10 prostate cancer have poor outcomes? Results from the SEARCH database. BJU Int 118: $250-257$.

Fradet V, Kurhanewicz J, Cowan JE, Karl A, Coakley FV, Shinohara K, Carroll PR. 2010. Prostate cancer managed with active surveillance: Role of anatomic MR imaging and MR spectroscopic imaging. Radiology 256: 176-183.

Ghai S, Haider MA. 2015. Multiparametric-MRI in diagnosis of prostate cancer. Indian J Urol 31: 194-201.

Gordetsky J, Epstein J. 2016. Grading of prostatic adenocarcinoma: Current state and prognostic implications. $\mathrm{Di}$ agn Pathol 11: 1-8.
Grabski B, Baeurle L, Loch A, Wefer B, Paul U, Loch T. 2011. Computerized transrectal ultrasound of the prostate in a multicenter setup (C-TRUS-MS): Detection of cancer after multiple negative systematic random and in primary biopsies. World J Urol 29: 573-579.

Haffner J, Lemaitre L, Puech P, Haber G-P, Leroy X, Jones JS, Villers A. 2011. Role of magnetic resonance imaging before initial biopsy: Comparison of magnetic resonance imaging-targeted and systematic biopsy for significant prostate cancer detection. BJU Int 108: E171-E178.

Hambrock T, Somford DM, Hoeks C, Bouwense SA, Huisman H, Yakar D, van Oort IM, Witjes JA, Futterer JJ, Barentsz JO. 2010. Magnetic resonance imaging guided prostate biopsy in men with repeat negative biopsies and increased prostate specific antigen. J Urol 183: 520-527.

Hambrock T, Somford DM, Huisman HJ, van Oort IM, Witjes JA, Hulsbergen-van de Kaa CA, Scheenen T, Barentsz JO. 2011. Relationship between apparent diffusion coefficients at 3.0-T MR imaging and Gleason grade in peripheral zone prostate cancer. Radiology 259: 453 461.

Hillner BE, Siegel BA, Hanna L, Duan F, Shields AF, Coleman RE. 2014. Impact of ${ }^{18} \mathrm{~F}$-fluoride PET in patients with known prostate cancer: Initial results from the National Oncologic PET Registry. J Nucl Med 55: 574-581.

Hodge KK, McNeal JE, Stamey TA. 1989. Ultrasound guided transrectal core biopsies of the palpably abnormal prostate. J Urol 142: 66-70.

Jadvar H. 2013. Imaging evaluation of prostate cancer with ${ }^{18} \mathrm{~F}$-fluorodeoxyglucose PET/CT: Utility and limitations. Eur J Nucl Med Mol Imaging 40: 5-10.

Jones JS, Patel A, Schoenfield L, Rabets JC, Zippe CD, MagiGalluzzi C. 2006. Saturation technique does not improve cancer detection as an initial prostate biopsy strategy. $J$ Urol 175: 485-488.

Kotzerke J, Volkmer BG, Neumaier B, Gschwend JE, Hautmann RE, Reske SN. 2002. Carbon-11 acetate positron emission tomography can detect local recurrence of prostate cancer. Eur J Nucl Med Mol Imaging 29: 1380-1384.

Kurhanewicz J, Vigneron DB. 2008. Advances in MR spectroscopy of the prostate. Magn Reson Imaging Clin N Am 16: $697-710$.

Kurhanewicz J, Vigneron DB, Nelson SJ. 2000. Three-dimensional magnetic resonance spectroscopic imaging of brain and prostate cancer. Neoplasia 2: 166-189.

Labanaris AP, Engelhard K, Zugor V, Nutzel R, Kuhn R. 2010. Prostate cancer detection using an extended prostate biopsy schema in combination with additional targeted cores from suspicious images in conventional and functional endorectal magnetic resonance imaging of the prostate. Prostate Cancer Prostatic Dis 13: 65-70.

Le JD, Stephenson S, Brugger M, Lu DY, Lieu P, Sonn GA, Natarajan S, Dorey FJ, Huang J, Margolis DJA, et al. 2014. Magnetic resonance imaging-ultrasound fusion biopsy for prediction of final prostate pathology. J Urol 192: 1367-1373.

Le JD, Tan N, Shkolyar E, Lu DY, Kwan L, Marks LS, Huang J, Margolis DJ, Raman SS, Reiter RE. 2015. Multifocality and prostate cancer detection by multiparametric magnetic resonance imaging: Correlation with whole-mount histopathology. Eur Urol 67: 569-576. 
Leek J, Lench N, Maraj B, Bailey A, Carr IM, Andersen S, Cross J, Whelan P, MacLennan KA, Meredith DM, et al. 1995. Prostate-specific membrane antigen: Evidence for the existence of a second related human gene. Br J Cancer 72: $583-588$

Li Y, Schiepers C, Lake R, Dadparvar S, Berenji GR. 2012. Clinical utility of ${ }^{18} \mathrm{~F}$-fluoride PET/CT in benign and malignant bone diseases. Bone 50: 128-139.

Li Y, Tang J, Fei X, Gao Y. 2013. Diagnostic performance of contrast enhanced ultrasound in patients with prostate cancer: A meta-analysis. Acad Radiol 20: 156-164.

Liu H, Moy P, Kim S, Xia Y, Rajasekaran A, Navarro V, Knudsen B, Bander NH. 1997. Monoclonal antibodies to the extracellular domain of prostate-specific membrane antigen also react with tumor vascular endothelium. Cancer Res 57: 3629-3634.

Liu IJ, Zafar MB, Lai YH, Segall GM, Terris MK. 2001. Fluorodeoxyglucose positron emission tomography studies in diagnosis and staging of clinically organ-confined prostate cancer. Urology 57: 108-111.

Luthi-Carter R, Barczak AK, Speno H, Coyle JT. 1998. Molecular characterization of human brain $N$-acetylated $\alpha$-linked acidic dipeptidase (NAALADase). J Pharmacol Exp Ther 286: 1020-1025.

Macheda ML, Rogers S, Best JD. 2005. Molecular and cellular regulation of glucose transporter (GLUT) proteins in cancer. J Cell Physiol 202: 654-662.

Margolis DJA. 2014. Multiparametric MRI for localized prostate cancer: Lesion detection and staging. BioMed Res Int 2014: 11.

Marks L, Young S, Natarajan S. 2013. MRI-ultrasound fusion for guidance of targeted prostate biopsy. Curr Opin Urol 23: 43-50.

Maurer T, Beer AJ, Wester HJ, Kübler H, Schwaiger M, Eiber M. 2014. Positron emission tomography/magnetic resonance imaging with ${ }^{68} \mathrm{Gallium}$-labeled ligand of prostatespecific membrane antigen: Promising novel option in prostate cancer imaging? Int J Urol 21: 1286-1288.

Maurer T, Eiber M, Schwaiger M, Gschwend JE. 2016. Current use of PSMA-PET in prostate cancer management. Nat Rev Urol 13: 226-235.

McClure TD, Margolis DJA, Reiter RE, Sayre JW, Thomas MA, Nagarajan R, Gulati M, Raman SS. 2012. Use of MR imaging to determine preservation of the neurovascular bundles at robotic-assisted laparoscopic prostatectomy. Radiology 262: 874-883.

McConathy J, Voll RJ, Yu W, Crowe RJ, Goodman MM. 2003. Improved synthesis of anti- $\left[{ }^{18} \mathrm{~F}\right] \mathrm{FACBC}$ : Improved preparation of labeling precursor and automated radiosynthesis. Appl Radiat Isot 58: 657-666.

Minamimoto R, Loening A, Jamali M, Barkhodari A, Mosci C, Jackson T, Obara P, Taviani V, Gambhir SS, Vasanawala $S$, et al. 2015. Prospective comparison of ${ }^{99 \mathrm{~m}}$ Tc-MDP scintigraphy, combined ${ }^{18} \mathrm{~F}-\mathrm{NaF}$ and ${ }^{18} \mathrm{~F}$-FDG PET/CT, and whole-body MRI in patients with breast and prostate cancer. J Nucl Med 56: 1862-1868.

Mohler JL, Kantoff PW, Armstrong AJ, Bahnson RR, Cohen M, D’Amico AV, Eastham JA, Enke CA, Farrington TA, Higano CS, et al. 2014. Prostate cancer, version 2.2014. J Natl Compr Cancer Netw 12: 686-718.
Mohler JL, Armstrong AJ, Bahnson RR, D'Amico AV, Davis BJ, Eastham JA, Enke CA, Farrington TA, Higano CS, Horwitz EM, et al. 2016. Prostate cancer, version 1.2016. J Natl Compr Cancer Netw 14: 19-30.

Moore CM, Robertson NL, Arsanious N, Middleton T, Villers A, Klotz L, Taneja SS, Emberton M. 2013. Imageguided prostate biopsy using magnetic resonance imaging-derived targets: A systematic review. Eur Urol 63: $125-140$.

Nanni C, Schiavina R, Rubello D, Ambrosini V, Brunocilla E, Martorana G, Fanti S. 2013. The detection of disease relapse after radical treatment for prostate cancer: Is anti-3- ${ }^{18}$ F-FACBC PET/CT a promising option? Nucl Med Commun 34: 831-833.

Natarajan S, Marks LS, Margolis D, Huang J, Macairan ML, Lieu P, Fenster A. 2011a. Clinical application of a 3D ultrasound-guided prostate biopsy system: Biopsy tracking and lesion targeting via real-time MRI/ultrasound fusion. Urol Oncol 29: 334-342.

Natarajan S, Marks LS, Margolis DJA, Huang J, Macairan ML, Lieu P, Fenster A. 2011b. Clinical application of a 3D ultrasound-guided prostate biopsy system. Urol Oncol 29: 334-342.

Oka S, Okudaira H, Yoshida Y, Schuster DM, Goodman MM, Shirakami Y. 2012. Transport mechanisms of trans1-amino-3-fluoro $\left[1-{ }^{14} \mathrm{C}\right]$ cyclobutanecarboxylic acid in prostate cancer cells. Nucl Med Biol 39: 109-119.

Okihara K, Kojima M, Nakanouchi T, Okada K, Miki T. 2000. Transrectal power Doppler imaging in the detection of prostate cancer. BJU Int 85: 1053-1057.

Oyama N, Akino H, Suzuki Y, Kanamaru H, Sadato N, Yonekura Y, Okada K. 1999. The increased accumulation of $\left[{ }^{18} \mathrm{~F}\right]$ fluorodeoxyglucose in untreated prostate cancer. Jpn J Clin Oncol 29: 623-629.

Oyama N, Miller TR, Dehdashti F, Siegel BA, Fischer KC, Michalski JM, Kibel AS, Andriole GL, Picus J, Welch MJ. 2003. ${ }^{11} \mathrm{C}$-acetate PET imaging of prostate cancer: Detection of recurrent disease at PSA relapse. J Nucl Med 44: $549-555$.

Park BK, Kim B, Kim CK, Lee HM, Kwon GY. 2007. Comparison of phased-array 3.0-T and endorectal 1.5-T magnetic resonance imaging in the evaluation of local staging accuracy for prostate cancer. J Comput Assist Tomogr 31: 534-538.

Park BK, Park JW, Park SY, Kim CK, Lee HM, Jeon SS, Seo SI, Jeong BC, Choi HY. 2011. Prospective evaluation of 3-T MRI performed before initial transrectal ultrasoundguided prostate biopsy in patients with high prostatespecific antigen and no previous biopsy. Am J Roentgenol 197: W876-W881.

Park BH, Jeon HG, Choo SH, Jeong BC, Seo SI, Jeon SS, Choi HY, Lee HM. 2014. Role of multiparametric 3.0Tesla magnetic resonance imaging in patients with prostate cancer eligible for active surveillance. BJU Int 113: 864-870.

Presti JC Jr, O’Dowd GJ, Miller MC, Mattu R, Veltri RW. 2003. Extended peripheral zone biopsy schemes increase cancer detection rates and minimize variance in prostate specific antigen and age related cancer rates: Results of a community multi-practice study. J Urol 169: 125-129. 
E.T. Miller et al.

Qayyum A. 2009. Diffusion-weighted imaging in the abdomen and pelvis: Concepts and applications. Radiographics 29: 1797-1810.

Rais-Bahrami S, Siddiqui MM, Turkbey B, Stamatakis L, Logan J, Hoang AN, Walton-Diaz A, Vourganti S, Truong H, Kruecker J, et al. 2013. Utility of multiparametric magnetic resonance imaging suspicion levels for detecting prostate cancer. J Urol 190: 1721-1727.

Ren J, Yuan L, Wen G, Yang J. 2016. The value of anti-1amino-3- ${ }^{18} \mathrm{~F}$-fluorocyclobutane-1-carboxylic acid PET/ $\mathrm{CT}$ in the diagnosis of recurrent prostate carcinoma: A meta-analysis. Acta Radiol 57: 487-493.

Reske SN, Blumstein NM, Glatting G. 2008. $\left[{ }^{11} \mathrm{C}\right]$ choline PET/CT imaging in occult local relapse of prostate cancer after radical prostatectomy. Eur J Nucl Med Mol Imaging 35: 9-17.

Reyes DK, Pienta KJ. 2015. The biology and treatment of oligometastatic cancer. Oncotarget 6: 8491-8524.

Roehl KA, Han M, Ramos CG, Antenor JAV, Catalona WJ. 2004. Cancer progression and survival rates following anatomical radical retropubic prostatectomy in 3,478 consecutive patients: Long-term results. J Urol 172: 910-914.

Roethke M, Anastasiadis AG, Lichy M, Werner M, Wagner P, Kruck S, Claussen CD, Stenzl A, Schlemmer HP, Schilling D. 2012. MRI-guided prostate biopsy detects clinically significant cancer: Analysis of a cohort of 100 patients after previous negative TRUS biopsy. World J Urol 30: 213-218.

Rowe SP, Macura KJ, Ciarallo A, Mena E, Blackford A, Nadal R, Antonarakis ES, Eisenberger MA, Carducci MA, Ross AE, et al. 2016. Comparison of prostate-specific membrane antigen-based ${ }^{18} \mathrm{~F}$-DCFBC PET/CT to conventional imaging modalities for detection of hormone-naive and castration-resistant metastatic prostate cancer. $J$ Nucl Med 57: 46-53.

Salminen E, Hogg A, Binns D, Frydenberg M, Hicks R. 2002. Investigations with FDG-PET scanning in prostate cancer show limited value for clinical practice. Acta Oncol 41: 425-429.

Sandblom G, Sörensen J, Lundin N, Häggman M, Malmström PU. 2006. Positron emission tomography with C11-acetate for tumor detection and localization in patients with prostate-specific antigen relapse after radical prostatectomy. Urology 67: 996-1000.

Sarkar S, Das S. 2016. A review of imaging methods for prostate cancer detection. Biomed Eng Comput Biol 7: $1-15$.

Scher HI, Heller G. 2000. Clinical states in prostate cancer: Toward a dynamic model of disease progression. Urology 55: 323-327.

Scher B, Seitz M, Albinger W, Tiling R, Scherr M, Becker HC, Souvatzogluou M, Gildehaus FJ, Wester HJ, Dresel S. 2007. Value of ${ }^{11} \mathrm{C}$-choline PET and PET/CT in patients with suspected prostate cancer. Eur J Nucl Med Mol Imaging 34: $45-53$.

Schiavina R, Scattoni V, Castellucci P, Picchio M, Corti B, Briganti A, Franceschelli A, Sanguedolce F, Bertaccini A, Farsad M, et al. 2008. ${ }^{11} \mathrm{C}$-choline positron emission tomography/computerized tomography for preoperative lymph-node staging in intermediate-risk and high-risk prostate cancer: Comparison with clinical staging nomograms. Eur Urol 54: 392-401.

Schiffmann J, Tennstedt P, Fischer J, Tian Z, Beyer B, Boehm K, Sun M, Gandaglia G, Michl U, Graefen M, et al. 2014. Does HistoScanning ${ }^{\mathrm{TM}}$ predict positive results in prostate biopsy? A retrospective analysis of 1,188 sextants of the prostate. World J Urol 32: 925-930.

Schiffmann J, Manka L, Boehm K, Leyh-Bannurah SR, Karakiewicz PI, Graefen M, Hammerer P, Salomon G. 2015. Controversial evidence for the use of HistoScanning ${ }^{\mathrm{TM}}$ in the detection of prostate cancer. World J Urol 33: $1993-$ 1999.

Schimmoller L, Quentin M, Arsov C, Lanzman RS, Hiester A, Rabenalt R, Antoch G, Albers P, Blondin D. 2013. Inter-reader agreement of the ESUR score for prostate MRI using in-bore MRI-guided biopsies as the reference standard. Eur Radiol 23: 3185-3190.

Schöder H, Herrmann K, Gonen M, Hricak H, Eberhard S, Scardino P, Scher HI, Larson SM. 2005. 2- $\left[{ }^{18} \mathrm{~F}\right]$ fluoro-2deoxyglucose positron emission tomography for the detection of disease in patients with prostate-specific antigen relapse after radical prostatectomy. Clin Cancer Res 11: 4761-4769.

Schuster DM, Savir-Baruch B, Nieh PT, Master VA, Halkar RK, Rossi PJ, Lewis MM, Nye JA, Yu W, Bowman FD, et al. 2011. Detection of recurrent prostate carcinoma with anti-1-amino-3- ${ }^{18}$ F-fluorocyclobutane-1-carboxylic acid PET/CT and ${ }^{111}$ In-capromab pendetide SPECT/ CT. Radiology 259: 852-861.

Schuster DM, Nanni C, Fanti S, Oka S, Okudaira H, Inoue Y, Sörensen J, Owenius R, Choyke P, Turkbey B, et al. 2014. Anti-1-amino-3- ${ }^{18}$ F-fluorocyclobutane-1-carboxylic acid: Physiologic uptake patterns, incidental findings, and variants that may simulate disease. J Nuclear Med 55: 1986-1992.

Sciarra A, Panebianco V, Ciccariello M, Salciccia S, Cattarino S, Lisi D, Gentilucci A, Alfarone A, Bernardo S, Passariello R, et al. 2010. Value of magnetic resonance spectroscopy imaging and dynamic contrast-enhanced imaging for detecting prostate cancer foci in men with prior negative biopsy. Clin Cancer Res 16: 1875-1883.

Segall G, Delbeke D, Stabin MG, Even-Sapir E, Fair J, Sajdak R, Smith GT. 2010. SNM practice guideline for sodium ${ }^{18}$ F-fluoride PET/CT bone scans 1.0. J Nuclear Med 51: $1813-1820$.

Seitz M, Shukla-Dave A, Bjartell A, Touijer K, Sciarra A, Bastian PJ, Stief C, Hricak H, Graser A. 2009. Functional magnetic resonance imaging in prostate cancer. Eur Urol 55: 801-814.

Shah ZK, Elias SN, Abaza R, Zynger DL, DeRenne LA, Knopp MV, Guo B, Schurr R, Heymsfield SB, Jia G. 2015. Performance comparison of 1.5-T endorectal coil MRI with 3.0-T nonendorectal coil MRI in patients with prostate cancer. Acad Radiol 22: 467-474.

Silver DA, Pellicer I, Fair WR, Heston WD, Cordon-Cardo C. 1997. Prostate-specific membrane antigen expression in normal and malignant human tissues. Clin Cancer Res 3: $81-85$.

Singh H, Canto EI, Shariat SF, Kadmon DOV, Miles BJ, Wheeler TM, Slawin KM. 2004. Predictors of prostate cancer after initial negative systematic 12 core biopsy. J Urol 171: 1850-1854. 
Smith TA. 2000. Mammalian hexokinases and their abnormal expression in cancer. Br J Biomed Sci 57: 170-178.

Somford DM, Hamoen EH, Fütterer JJ, van Basten JP, Hulsbergen-van de Kaa CA, Vreuls W, van Oort IM, Vergunst H, Kiemeney LA, Barentsz JO, et al. 2013. The predictive value of endorectal 3 tesla multiparametric magnetic resonance imaging for extraprostatic extension in patients with low, intermediate and high risk prostate cancer. $J$ Urol 190: 1728-1734.

Sonn GA, Natarajan S, Margolis DJA, MacAiran M, Lieu P, Huang J, Dorey FJ, Marks LS. 2013. Targeted biopsy in the detection of prostate cancer using an office based magnetic resonance ultrasound fusion device. $J$ Urol 189: 86-92.

Sonn GA, Chang E, Natarajan S, Margolis DJ, Macairan M, Lieu P, Huang J, Dorey FJ, Reiter RE, Marks LS. 2014 Value of targeted prostate biopsy using magnetic resonance-ultrasound fusion in men with prior negative biopsy and elevated prostate-specific antigen. Eur Urol 65: 809-815.

Souvatzoglou M, Eiber M, Takei T, Furst S, Maurer T, Gaertner F, Geinitz H, Drzezga A, Ziegler S, Nekolla SG, et al. 2013. Comparison of integrated whole-body $\left[{ }^{11} \mathrm{C}\right]$ choline $\mathrm{PET} / \mathrm{MR}$ with $\mathrm{PET} / \mathrm{CT}$ in patients with prostate cancer. Eur J Nucl Med Mol Imaging 40: 1486-1499.

Stamatakis L, Siddiqui MM, Nix JW, Logan J, Rais-Bahrami S, Walton-Diaz A, Hoang AN, Vourganti S, Truong H, Shuch B, et al. 2013. Accuracy of multiparametric magnetic resonance imaging in confirming eligibility for active surveillance for men with prostate cancer. Cancer 119: 3359-3366.

Stewart CS, Leibovich BC, Weaver AL, Lieber MM. 2001. Prostate cancer diagnosis using a saturation needle biopsy technique after previous negative sextant biopsies. $J$ Urol 166: 86-91; discussion 91-82.

Storz E, Shah A, Zettinig O, Eiber M, Wester HJ, Kübler H, Gschwend JE, Schwaiger M, Frisch B, Maurer T. 2015. PSMA-PET/MRI-guided transrectal fusion biopsy for the detection of prostate cancer. EAU15-30th Annual Congress of the European Association of Urology, Abstract 217. Madrid, March 20-24.

Tagawa ST, Beltran H, Vallabhajosula S, Goldsmith SJ, Osborne J, Matulich D, Petrillo K, Parmar S, Nanus DM, Bander NH. 2010. Anti-prostate specific membrane antigen-based radioimmunotherapy for prostate cancer. Cancer 116: 1075-1083.

Tagawa ST, Milowsky MI, Morris M, Vallabhajosula S, Christos P, Akhtar NH, Osborne J, Goldsmith SJ, Larson S, Taskar NP, et al. 2013. Phase II study of Lutetium-177labeled anti-prostate-specific membrane antigen monoclonal antibody J591 for metastatic castration-resistant prostate cancer. Clin Cancer Res 19: 5182-5191.

Taira AV, Merrick GS, Galbreath RW, Andreini H, Taubenslag W, Curtis R, Butler WM, Adamovich E, Wallner KE. 2010. Performance of transperineal template-guided mapping biopsy in detecting prostate cancer in the initial and repeat biopsy setting. Prostate Cancer Prostatic Dis 13: 71-77.

Tan CH, Paul Hobbs B, Wei W, Kundra V. 2015. Dynamic contrast-enhanced MRI for the detection of prostate can cer: Meta-analysis. Am J Roentgenol 204: W439-W448.
Taneja SS. 2004. ProstaScint ${ }^{\circledR}$ scan: Contemporary use in clinical practice. Rev Urol 6: S19-S28.

Tateishi U, Morita S, Taguri M, Shizukuishi K, Minamimoto R, Kawaguchi M, Murano T, Terauchi T, Inoue T, Kim EE. 2010. A meta-analysis of ${ }^{18} \mathrm{~F}$-fluoride positron emission tomography for assessment of metastatic bone tumor. Clin Nuclear Med 24: 523-531.

Testa C, Schiavina R, Lodi R, Salizzoni E, Corti B, Farsad M, Kurhanewicz J, Manferrari F, Brunocilla E, Tonon C, et al. 2007. Prostate cancer: Sextant localization with MR imaging, MR spectroscopy, and ${ }^{11} \mathrm{C}$-choline PET/CT. Radiology 244: 797-806.

Tiffany CW, Lapidus RG, Merion A, Calvin DC, Slusher BS. 1999. Characterization of the enzymatic activity of PSM: Comparison with brain NAALADase. Prostate 39: 28-35.

Turkbey B, Shah VP, Pang Y, Bernardo M, Xu S, Kruecker J, Locklin J, Baccala AA Jr, Rastinehad AR, Merino MJ, et al. 2011. Is apparent diffusion coefficient associated with clinical risk scores for prostate cancers that are visible on 3-T MR images? Radiology 258: 488-495.

Turkbey B, Mani H, Aras O, Ho J, Hoang A, Rastinehad AR, Agarwal H, Shah V, Bernardo M, Pang Y, et al. 2013. Prostate cancer: Can multiparametric MR imaging help identify patients who are candidates for active surveillance? Radiology 268: 144-152.

Ulmert D, Solnes L, Thorek DLJ. 2015. Contemporary approaches for imaging skeletal metastasis. Bone Res 3: 15024.

Vargas HA, Akin O, Afaq A, Goldman D, Zheng J, Moskowitz CS, Shukla-Dave A, Eastham J, Scardino P, Hricak H. 2012. Magnetic resonance imaging for predicting prostate biopsy findings in patients considered for active surveillance of clinically low risk prostate cancer. J Urol 188: 1732-1738.

Verma S, Rajesh A, Morales H, Lemen L, Bills G, Delworth M, Gaitonde K, Ying J, Samartunga R, Lamba M. 2011. Assessment of aggressiveness of prostate cancer: Correlation of apparent diffusion coefficient with histologic grade after radical prostatectomy. Am J Roentgenol 196: 374-381.

Verma S, Turkbey B, Muradyan N, Rajesh A, Cornud F, Haider MA, Choyke PL, Harisinghani M. 2012. Overview of dynamic contrast-enhanced MRI in prostate cancer diagnosis and management. Am J Roentgenol 198: 1277-1288.

Villers A, Puech P, Mouton D, Leroy X, Ballereau C, Lemaitre L. 2006. Dynamic contrast enhanced, pelvic phased array magnetic resonance imaging of localized prostate cancer for predicting tumor volume: Correlation with radical prostatectomy findings. $J$ Urol 176: 2432-2437.

Walsh PC, Lepor H, Eggleston JC. 1983. Radical prostatectomy with preservation of sexual function: Anatomical and pathological considerations. Prostate 4: 473-485.

Weineisen M, Simecek J, Schottelius M, Schwaiger M, Wester HJ. 2014. Synthesis and preclinical evaluation of DOTAGA-conjugated PSMA ligands for functional imaging and endoradiotherapy of prostate cancer. EJNMMI Res 4: 63.

Weinreb JC, Barentsz JO, Choyke PL, Cornud F, Haider MA, Macura KJ, Margolis D, Schnall MD, Shtern F, Tempany CM, et al. 2016. PI-RADS prostate imag- 
E.T. Miller et al.

ing_-Reporting and data system: 2015, version 2. Eur Urol 69: 16-40.

Welch HG, Fisher ES, Gottlieb DJ, Barry MJ. 2007. Detection of prostate cancer via biopsy in the Medicare-SEER population during the PSA era. J Natl Cancer Inst 99: 1395- 1400 .

Wilt TJ, Brawer MK, Jones KM, Barry MJ, Aronson WJ, Fox S, Gingrich JR, Wei JT, Gilhooly P, Grob BM, et al. 2012. Radical prostatectomy versus observation for localized prostate cancer. N Engl J Med 367: 203-213.

Wysock JS, Rosenkrantz AB, Huang WC, Stifelman MD, Lepor H, Deng F-M, Melamed J, Taneja SS. 2014. A prospective, blinded comparison of magnetic resonance (MR) Imaging-ultrasound fusion and visual estimation in the performance of MR-targeted prostate biopsy: The PROFUS trial. Eur Urol 66: 343-351.

Yamaguchi T, Lee J, Uemura H, Sasaki T, Takahashi N, Oka T, Shizukuishi K, Endou H, Kubota Y, Inoue T. 2005.
Prostate cancer: A comparative study of ${ }^{11} \mathrm{C}$-choline PET and MR imaging combined with proton MR spectroscopy. Eur J Nucl Med Mol Imaging 32: 742-748.

Zaytoun OM, Moussa AS, Gao T, Fareed K, Jones JS. 2011. Office based transrectal saturation biopsy improves prostate cancer detection compared to extended biopsy in the repeat biopsy population. J Urol 186: 850-854.

Zelefsky MJ, Eastham JA, Cronin AM, Fuks Z, Zhang Z, Yamada Y, Vickers A, Scardino PT. 2010. Metastasis after radical prostatectomy or external beam radiotherapy for patients with clinically localized prostate cancer: A comparison of clinical cohorts adjusted for case mix. J Clin Oncol 28: 1508-1513.

Zhai L, Polascik TJ, Foo WC, Rosenzweig S, Palmeri ML, Madden J, Nightingale KR. 2012. Acoustic radiation force impulse imaging of human prostates: Initial in vivo demonstration. Ultrasound Med Biol 38: 50-61. 


\section{$\&_{\mathrm{CSH}}^{\infty} \&$ Cold Spring Harbor

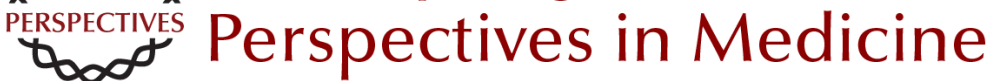

\section{Anatomic and Molecular Imaging in Prostate Cancer}

Eric T. Miller, Amirali Salmasi and Robert E. Reiter

Cold Spring Harb Perspect Med 2018; doi: 10.1101/cshperspect.a030619 originally published online July 14,2017

\section{Subject Collection Prostate Cancer}

Anatomic and Molecular Imaging in Prostate Cancer

Eric T. Miller, Amirali Salmasi and Robert E. Reiter

The Epidemiology of Prostate Cancer

Claire H. Pernar, Ericka M. Ebot, Kathryn M. Wilson, et al.

Prostate Stem Cells and Cancer Stem Cells Jia J. Li and Michael M. Shen

Prostate Cancer Epigenetics: From Basic Mechanisms to Clinical Implications Srinivasan Yegnasubramanian, Angelo M. De Marzo and William G. Nelson

\section{The Genomics of Prostate Cancer: A Historic} Perspective Mark A. Rubin and Francesca Demichelis

Neuroendocrine Differentiation in Prostate

Cancer: Emerging Biology, Models, and Therapies Loredana Puca, Panagiotis J. Vlachostergios and Himisha Beltran

DNA Damage Response in Prostate Cancer Matthew J. Schiewer and Karen E. Knudsen

Transcriptional Regulation in Prostate Cancer David P. Labbé and Myles Brown
New Opportunities for Targeting the Androgen Receptor in Prostate Cancer Margaret M. Centenera, Luke A. Selth, Esmaeil Ebrahimie, et al.

Prostate Cancer Research at the Crossroads Michael M. Shen and Mark A. Rubin

Immunotherapy for Prostate Cancer Nicholas J. Venturini and Charles G. Drake

Molecular Pathology of High-Grade Prostatic Intraepithelial Neoplasia: Challenges and Opportunities Levent Trabzonlu, Ibrahim Kulac, Qizhi Zheng, et al.

Metastases in Prostate Cancer Federico La Manna, Sofia Karkampouna, Eugenio Zoni, et al.

Genetically Engineered Mouse Models of Prostate Cancer in the Postgenomic Era Juan M. Arriaga and Cory Abate-Shen

Molecular Biomarkers in the Clinical Management of Prostate Cancer Aaron M. Udager and Scott A. Tomlins

Metabolic Vulnerabilities of Prostate Cancer: Diagnostic and Therapeutic Opportunities Giorgia Zadra and Massimo Loda

For additional articles in this collection, see http://perspectivesinmedicine.cshlp.org/cgi/collection/ 